\title{
PREVENÇÃO DE RACHADURA DE TOPO DE TORA E DE PEÇAS SERRADAS EM Eucalyptus citriodora Hook
}

\author{
WINTER ÉRIK DE OLIVEIRA
}

Engenheiro Florestal

Orientador: Prof. Dr. JOSÉ NIVALDO GARCIA

Dissertação apresentada à Escola Superior de Agricultura "Luiz de Queiroz", Universidade de São Paulo, para obtenção do título de Mestre em Recursos Florestais, com opção em Tecnologia de Produtos Florestais.

\author{
PI R A C I C A B A \\ Estado de São Paulo - Brasil \\ Agosto - 2003
}


Winter Érik de Oliveira. Prevenção de rachadura de topo de tora e de peças serradas em Eucalyptus citriodora Hook.

\begin{tabular}{|c|c|c|c|c|}
\hline p. & item & linha & onde se lê & leia-se \\
\hline xiii & no título & primeira & sawed & sawn \\
\hline 4 & 2.1 .1 & nona & $\begin{array}{l}\text { Segundo Garcia (1992), que as } \\
\text { tensões de ... }\end{array}$ & $\begin{array}{l}\text { Segundo Garcia } \\
\text { tensões de... }\end{array}$ \\
\hline 10 & 2.2 .2 & sexta & $\begin{array}{l}\text {...as tensões longitudinais são em } \\
\text { geral são as... }\end{array}$ & $\begin{array}{l}\text {...as tensões longitudinais, em } \\
\text { geral, são as... }\end{array}$ \\
\hline 14 & 2.3 .1 & oitava & $\begin{array}{l}\text {...tensão elástica tangencial no ou } \\
\text { ao anelamento. }\end{array}$ & $\begin{array}{l}\text {...tensão elástica tangencial a } \\
\text { anelamento. }\end{array}$ \\
\hline 19 & 2.4 & oitava & $\begin{array}{l}\text {...no sentido medula-casca e } \\
\text { concluem... }\end{array}$ & $\begin{array}{l}\text {...no sentido medula-casca } \\
\text { conclui... }\end{array}$ \\
\hline 22 & 3.2.2.1 & prim & ...como descrito acima,... & ...como descrito na Figura $4, \ldots$ \\
\hline 23 & 3.2 .2 .2 & terce & cionamento... & ...durante o secc \\
\hline 30 & 3.5 & non & ...testada através do teste $F$. & $\begin{array}{l}\ldots \text { testada atrav } \\
\text { nível de } 5 \% \text { de }\end{array}$ \\
\hline 32 & 4.1 & Tabela 2 & $\begin{array}{l}\text { Anelamento } 1,24^{b} \\
\text { Chanfro } 0,78^{a} \\
\text { Testemunha } 0,33^{a b}\end{array}$ & $\begin{array}{l}\text { Anelamento } 0,33^{a b} \\
\text { Chanfro } 1,24^{b} \\
\text { Testemunha } 0,78^{a}\end{array}$ \\
\hline 35 & 4.5 & quin & Notou-se a nível de tendência... & Notou-se ao nível de tendência... \\
\hline 36 & 4.6 & Prim & $\begin{array}{l}\text { Conforme mostra a Figura } 17, \\
\text { observou-se que o diâmetro... }\end{array}$ & $\begin{array}{l}\text { Conforme mostra a Figura } 17, \\
\text { diâmetro... }\end{array}$ \\
\hline 39 & 4.7 & $\mathrm{~F}$ & $\begin{array}{l}\text { Piche } 39,66 \\
\text { Testemunha } 36,9\end{array}$ & $\begin{array}{l}\text { Piche } 40,50 \\
\text { Testemunha } 38,83\end{array}$ \\
\hline 41 & 5 & & $\begin{array}{l}\text { Ainda a nível de tendência, o } \\
\text { anelamento... }\end{array}$ & $\begin{array}{l}\text { Ainda ao nível de tend } \\
\text { anelamento... }\end{array}$ \\
\hline
\end{tabular}




\section{Dados Internacionais de Catalogação na Publicação (CIP) DIVISÃO DE BIBLIOTECA E DOCUMENTAÇÃO - ESALO/USP}

Oliveira, Winter Érik de Prevençāo de rachadura de topo de tora e de peças serradas em Eucalyptus citriodora Hook / Winter Érik de Oliveira. - P Piracicaba, 2003.

50 p. : il.

Dissertação (mestrado) - . Escola Superior de Agricultura Luiz de Queiroz, 2003.

Bibliografia.

1. Eucalipto 2. Madeira serrada 3. Rachadura 4. Tecnologia da madeira I. Título

CDD 674.142 
As minhas três Mães:Silvia (in memorian), Tia Maroca (in memorian), Tia Luzia e ao meu Pai e Amigo José da Silva Neto que não mediram esforços para a conquista de mais essa vitória em nossas vidas OFEREÇO.

Aos meus irmãos, Tarley, Vitória, Érika, Fábio, Ivani, Meire, Josiane, Eliane, Verenice, Sônia e Osmane DEDICO. 


\section{AGRADECIMENTOS}

Primeiramente a Deus.

Ao Departamento de Ciências Florestais da ESAL/USP, pela oportunidade de realização do curso de Pós-Graduação.

Ao Professor Dr. José Nivaldo Garcia, pela confiança, ensinamentos, incentivo e amizade.

Aos Professores Dr. Geraldo Bortoletto Júnior, Prof ${ }^{a}$ Dra. Adriana Nollasco e Prof - Dra. Maria Cristina Stolf Nogueira pelas sugestões e correções deste trabalho.

Ao Professor José Luis Stape por ter cedido o material utilizado no estudo.

A CAPES - Coordenação de Aperfeiçoamento de Pessoal de Nivel Superior, pelo auxílio financeiro que permitiu a execução deste trabalho.

À CAVE/COSEAS/PCLQ, pela concessão da moradia.

Ao Éder de Abreu grande incentivador para o busca do conhecimento.

Ao Luís Eduardo Facco, técnico do Laboratório de Engenharia da Madeira da ESALQ/USP e ao Valdir Ferreira Caldas, técnico do Laboratório de Laminação da Madeira, pela colaboração prestada na coleta dos dados e apoio técnico.

Ao setor de carpintaria da ESALQ: Liu, Sr. Wilson, Sidnei, Natal, Palhinha, Magrão, Biro-Biro, Branco e Juquinha pelos serviços prestados e desdobro da madeira. 
Aos amigos e companheiros de todas as horas: Fábio, Ariel Mané, Maria Claúdia, Ana Claúdia Lira, Mario Ferraro, Ana Clara, Luciane Zaia, Rosana Zaia, Adriana Francine, Wirifran.

Aos velhos amigos Marquinho, Everton (in memorian) e William.

À toda diretoria do Golf's Club.

Ao Marcelino Carneiro Guedes pela grande amizade, pela ajuda nas análises e na luta pelos direitos dos alunos da Pós-Graduação.

À Viviane pela ajuda prestada na finalização deste trabralho.

Aos amigos Ivo Rosa Filho, Rogério Oliveira Naressi e Evandro Del Amatrice pela ajuda do dia a dia e pela paciência.

Aos amigos da Vila PG Antônio Maria das Chagas Pessoa, Alailson Venceslau Santiago, Antônio Baptista e Luiz Fernando Caldeira Ribeiro pelos momentos agradáveis ao longo de nossa estadia na VILA ESTUDANTIL.

À Margarete Z. Pinese e ao Alexandre Halli Najm pela ajuda nas questões burocráticas e pela paciência.

Aos amigos piracicabanos Pointer, Necão, Jorge, Pedrinho.

À Bibliotecária Silvia pelas correções dessa Dissertação.

À Luciana Castro e ao Quelmo pela amizade e companheirismo.

À Sociedade que mesmo sem saber custeou esse curso. 


\section{SUMÁRIO}

Página

LISTA DE FIGURAS ...................................................................... viii

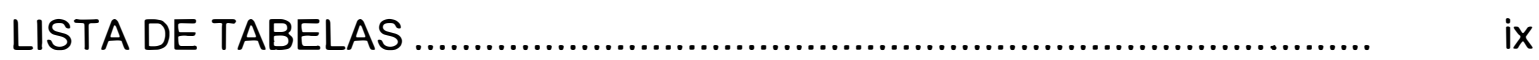

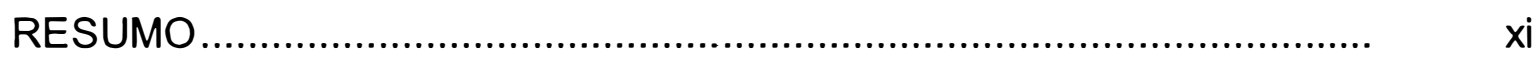

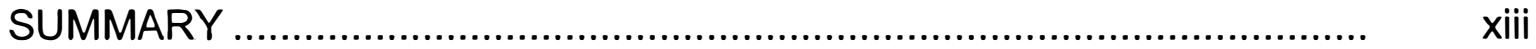

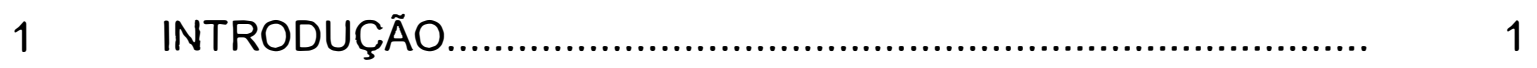

2 REVISÃO DE LITERATURA …...............................................

$2.1 \quad$ Tensões de crescimento ..........................................................

2.1.1 Definições e Origem ................................................................ 4

2.2 Consequências das tensões de crescimento ................................. 6

2.2.1 Rachaduras de extremidades de tora......................................... 7

2.2.2 Rachaduras em extremidades de tábuas .................................... 9

2.2.3 Cerne quebradiço .................................................................. 12

2.3 Técnicas de minimização de rachaduras........................................ 12

2.3.1 Anelamento .................................................................... 13

2.3.2 Corte em Bisel .................................................................. 15

2.3.3 Proteção do topo da tora com Piche............................................. 15

2.4 Desdobro ........................................................................... 15

3 MATERIAL E MÉTODOS ..................................................... 20

3.1 Matéria Prima …................................................................ 20

3.2 Tratamentos aplicados ….................................................. 20

3.2.1 Classe diamétrica ................................................................ 20

3.2.2 Técnicas de prevenção ou minimização de rachaduras................ 21 


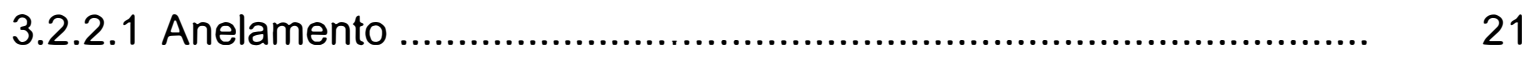

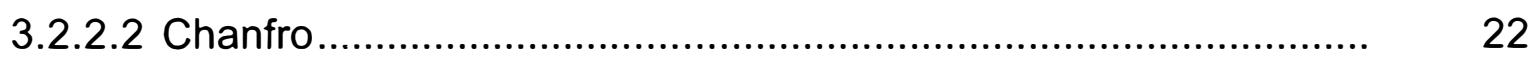

3.2.2.3 Proteção do topo da tora com Piche............................................ 24

3.2.3 Tempos de armazenamento.................................................... 25

3.3 Estudo da taxa de propagação das rachaduras, no sentido radial e longitudinal da tora........................................................... 26

3.3.1 Medição das rachaduras de topo de toras..................................... 28

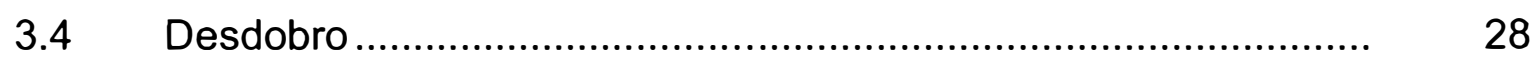

3.4.1 Medição das rachaduras de extremidade de tábua....................... 29

3.5 Delineamento Experimental e Análise Estatística........................ 30

$4 \quad$ RESULTADOS E DISCUSSÃO .............................................. 31

4.1 Análise estatística para o índice de rachadura de tora (IR) .......... 31

4.2 Influência da classe diamétrica da tora....................................... 33

4.3 Influência do tempo de armazenamento na rachadura de extremidade da tora ............................................................. 33

4.4 Análise estatística para o índice de rachadura de tábua $(\mathrm{Rt})$....... $\quad 34$

4.5 Influência do tempo de armazenamento nas rachaduras de extremidade de tábua ......................................................... $\quad 35$

4.6 Rachadura de extremidade de tábua em função da classe

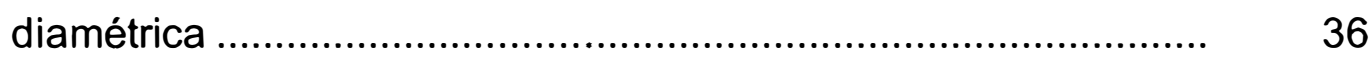

4.7 Avaliação de perdas devido as técnicas: anelamento e chanfro .. $\quad 37$

4.8 Estudo da taxa de propagação das rachaduras, no sentido radial e longitudinal da tora................................................................... 40

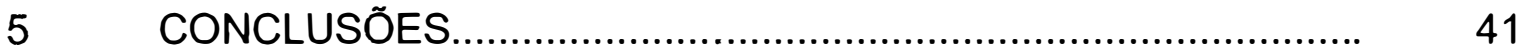

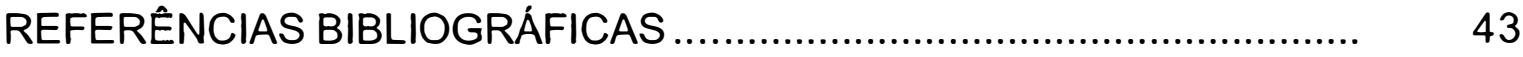




\section{LISTA DE FIGURAS}

Página

1 Curvas de distribuição de tensões de crescimento ao longo do raio de uma árvore de $60 \mathrm{~cm}$, segundo os modelos de Kubler (1959) e Garcia (1995)

2 Rachadura de extremidade de tora de Eucalyptus citriodora, logo após a derrubada e seccionamento da árvore...

3a Rachadura de extremidade de tábua de Eucalyptus citriodora durante desdobro.

3b Rachadura de extremidade de tábua de Eucalyptus citriodora devido ao desdobro e presença de tensões residuais na tora..........

$4 \quad$ Aspecto da tora após o anelamento .................................................. 21

5 Ilustração das etapas de anelamento das toras................................. 22

6 Gabarito utilizado para realização do corte em chanfro com ângulo de $60^{\circ}$

7 Simulação do corte da tora em chanfro.

8 Aspecto da tora após vedação do topo da tora com piche.................

9 Aplicação de tinta em uma das extremidades da tora........................

10 Método de desdobro visando tábuas tangenciais, com desdobro principal utilizando serra de fita simples.

11 Rachaduras de extremidades de tábua...

12 Médias de índice de rachadura de extremidade de tora em função do tipo de técnica de prevenção.

13 Rachadura de extremidade de tora em função da classe diamétrica. 
14 Índice de rachadura de extremidade de tora segundo diferentes tempos de armazenamento.

15 Médias de índice de rachadura de extremidades de tábua em função do tipo de técnica de prevenção............................................

16 Índice de rachadura de extremidade de tábua das técnicas de prevenção de rachaduras nos tempos de armazenamento.............. 36

17 Rachadura de extremidade de tábua em função da classe diamétrica

18 Esquema de medição das perdas de tábuas em comprimento para o anelamento

19 Esquema de medição das perdas de tábuas em comprimento para o chanfro

20 Perda média das tábuas em comprimento em função das técnicas . 


\section{LISTA DE TABELAS}

Página

$1 \quad$ Análise de variância para variável IR (\%) ..................................... 31

2 Comparação entre as médias das diferentes técnicas de prevenção pelo teste de Tukey ........................................................ 32

$3 \quad$ Análise de variância para variável $\mathrm{Rt}(\mathrm{cm})$...................................... 34

4 Análise de variância para perda de madeira no comprimento das tábuas $\mathrm{cm}$ )...................................................................... 37

5 Comparação entre as médias das perdas de comprimento de tábuas $(\mathrm{cm})$ pelo teste de Tukey .................................................. 38 


\title{
PREVENÇÃO DE RACHADURA DE TOPO DE TORA E DE PEÇAS SERRADAS EM Eucalyptus citriodora Hook
}

\author{
Autor: WINTER ÉRIK DE OLIVEIRA \\ Orientador: Prof. Dr. JOSÉ NIVALDO GARCIA
}

\section{RESUMO}

O presente estudo teve por objetivo avaliar o efeito de rachaduras de topo de tora, oriundas da liberação das tensões de crescimento, sobre rachaduras de peça serrada. As razões da pesquisa baseiam-se na necessidade de se encontrar uma forma de simplificar a quantificação das rachaduras de extremidade de tora, ou seja, identificar qual das rachaduras de topo de tora é a mais importante na limitação do comprimento útil da peça serrada. Em complementação, foram testadas quatro diferentes técnicas de minimização de rachadura de extremidade de toras. O experimento foi realizado com Eucalyptus citriodora de 23 anos de idade. Foram analisadas 72 toras, de 2 metros de comprimento, com diâmetros compreendidos em duas classes de diâmetro, cujo os centros foram de $18 \mathrm{~cm}$ e $23 \mathrm{~cm}$. Essas toras foram distribuídas em três lotes para representarem três diferentes tempos de armazenamento. Em seguida foram aplicadas as técnicas de prevenção ou minimização de rachaduras de extremidades de tora, sendo elas: anelamento, aplicação de piche no topo da tora e chanfro. A testemunha foi a técnica normalmente usada, de cortes de seccionamento da árvore em toras 
perpendiculares ao seu eixo e sem nenhum tratamento do topo da tora. Depois de realizadas as técnicas foi despejada tinta, bem diluída nas rachaduras de topo de tal forma a permitir que a tinta alcançasse toda a extensão do comprimento longitudinal das rachaduras. Em seguida, procedeu-se o desdobro das toras, sendo o primeiro, segundo e terceiro lotes desdobrados nos tempos respectivos de 7, 14 e 21 dias depois do seccionamento do tronco da árvore em toras. Depois do desdobro foram efetuadas as medições do comprimento das rachaduras de extremidade de tábua. Os resultados mostraram que a variável rachadura de extremidade de tora não sofreu influência nem do diâmetro e nem do tempo de armazenamento das toras. Entretanto a técnica de prevenção de rachadura influenciou significativamente nas rachaduras de tora. Para a variável rachadura de tábua os resultados encontrados mostraram que essa variável não sofreu influência do diâmetro da tora, do tempo de armazenamento e da técnica de prevenção de rachaduras de extremidade de tora. Foi avaliada a perda de comprimento da tábua em função das técnicas de prevenção de rachaduras aplicadas nas toras, verificando-se que o chanfro e o anelamento perderam 18 e 20 centímetro respectivamente, devido à técnica. Já na perda por rachadura efetiva, o chanfro foi a técnica que apresentou maior perda. A metodologia desenvolvida para a verificação de qual rachadura de topo de tora principal, ou seja, aquela que tem maior importância na limitação do comprimento útil da peça serrada demostrou não ser suficientemente consistente.

Palavras chave: Eucalipto, Madeira Serrada, Rachadura, Tecnologia da madeira. 


\title{
PREVENTION END SPLITTING OF LOG AND SAWED WOOD IN EucalyptuS citriodora Hook
}

\author{
Author: WINTER ÉRIK DE OLIVEIRA \\ Adviser: Prof. Dr. JOSÉ NIVALDO GARCIA
}

\section{SUMMARY}

The main objective of this study was to evaluate the effect of log end splitting, due to growth stresses relief, on board end splitting. The reasons of the research is based on the necessity of finding a way to simplify the evaluation of log end splitting or to identify which of existing log cracks is the most important in board length reduction. In addition four different techniques to reduce log end splitting cracks were used. The experiment was carried out utilizing 72 logs, two meters long, of a 23 year-old grown Eucalyptus citriodora, belonging to two diameter classes which had 18 and $23 \mathrm{~cm}$ as classes centers. These logs were separated into three different set to be tested in three different times of log storage. Then the following techniques to prevent log end splitting were applied: girdling, pitch deposition on the top of the log, inclined cut 60 degrees from the log axis and the blank was the technique normally used, where cuts are perpendicular to the log axis and no treatment is applied on log end. After doing log end splitting prevention technique procedures, diluted inks were dropped into cracks of the log end which was positioned in the vertical position 
for permitting ink to reach the entire depth of the longest crack.. Then, the logs were sawed, being the first, second and third sets tested respectively after 7,14 and 21 days after trees felling. After sawing, measurements of board end cracks were taken. The results showed that the cracks on the log extremity are not influenced neither by log diameters nor the period of log storage but are influenced by the technique employed to prevent the cracks. However the results showed that the cracks on the board extremity is not influenced by the log diameter, by the time of storage and by the technique employed to prevent the cracks. The board length loss was measured and the results showed 18 and $20 \mathrm{~cm}$ of loss, respectively to inclined cut and girdling techniques, but effective cracks loss was considered higher in inclined cut technique. The methodology developed to identify the principal crack at log end, that mean the crack which has the most importance on net board length was considered not sufficiently consistent.

Key words: Eucalypt, sawn wood, cracks, wood technology 


\section{INTRODUÇÃO}

O setor madeireiro no Brasil tem sido marcado por um processo de utilização crescente de madeiras provenientes de reflorestamentos. Tal fato tem se tornado mais evidente nos últimos anos, sobretudo em razão dos questionamentos existentes em relação à exploração das florestas nativas, quer seja por razões ecológicas, quer seja pela elevação dos preços de suas madeiras devida às dificuldades da exploração da floresta tropical e às grandes distâncias entre as zonas de produção e de consumo.

Com a redução da disponibilidade mundial de madeira de florestas tropicais e com as restrições à continuidade da utilização indiscriminada desse tipo de florestas para fornecimento de madeira de uso industrial, as espécies de Eucalyptus passaram a constituir uma alternativa, que se torna cada vez mais importante no abastecimento de indústrias madeireiras (Oliveira et al., 2000).

Sua capacidade produtiva, adaptabilidade a diversos ambientes e, sobretudo, a expressiva diversidade de espécies que possui, tornando possível atender os requisitos tecnológicos dos mais diversos segmentos da produção industrial madeireira, são os principais atributos que tornam esse gênero importante como fonte de matéria prima (Assis, 1999).

Apesar da eucaliptocultura brasileira ter demonstrado ser uma das mais produtivas, avançadas e competitivas do mundo, até o presente momento essas vantagens têm sido aproveitadas somente pela indústria de celulose e papel, de painéis de madeira reconstituída e siderúrgica.

A pouca utilização do eucalipto para a obtenção de madeira serrada se deve à presença de algumas características que dificultam o seu desdobro. Dentre estas características, as tensões de crescimento são as mais 
importantes, sendo responsáveis por vários defeitos como rachaduras de topo e empenamentos, que inviabilizam o seu uso (Ponce, 1995).

De acordo com Rocha (2000), para se obter madeira serrada de eucalipto de boa qualidade é necessário o esforço de vários ramos da pesquisa, como a escolha de espécies mais adequadas, técnicas de melhoramento genético, manejo, exploração adequada e processamento de desdobro e secagem apropriada.

Com relação à utilização do Eucalyptus nas indústrias de processamento mecânico da madeira, pouco tem sido feito. A produção anual de madeira serrada de eucalipto no Brasil situa-se em torno de $\mathbf{4 0 0}$ mil metros cúbicos, isto é, apenas $1,8 \%$ da produção nacional de madeira serrada (STCP, 2000).

A pouca participação da madeira de eucalipto no mercado como madeira serrada é devida a baixa disponibilidade de material de qualidade para pronto uso e, principalmente, à desinformação e aos preconceitos sobre o comportamento da madeira nos produtos acabados, havendo ainda uma crença de que a madeira de eucalipto racha demasiadamente e deforma, inviabilizando o uso de qualquer peça acabada. Isto se deve ao fato de que a madeira de eucalipto apresenta certas características que levam a deformações, rachaduras, empenamentos e vários outros defeitos. Porém, tais limitações de uso podem ser minimizadas através de procedimentos genéticos e silviculturais adicionados a técnicas corretas de processamento (Silva, 2002).

De acordo com estudos realizados sobre rachaduras de extremidades de toras e de tábuas, foi possivel propor como hipótese de trabalho que a rachadura de topo de tora de maior largura seja o principal fator limitante no comprimento útil da madeira serrada, ou seja, essa rachadura, aqui chamada de principal, é a que atinge maior profundidade longitudinal na tora.

Outras hipóteses foram testadas no estudo, sendo elas: as técnicas de prevenção de rachaduras de topo de toras são diferentes quanto à minimização de rachaduras; o tempo de armazenamento das toras tem 
influência no índice de rachadura; as rachaduras de topo de tora sofre influência do diâmetro da tora.

A presente pesquisa teve como objetivo buscar alternativas que viabilizem a utilização de Eucalyptus citriodora para produção de madeira serrada, com a redução de perdas por rachadura de topo de tora e de peças serradas.

Para a realização desta pesquisa foram estabelecidos os seguintes objetivos:

- avaliar diferentes técnicas de prevenção ou minimização de rachaduras de topo de tora bem como verificar a sua eficácia ao longo do tempo de armazenamento da tora e da classe de diâmetro;

- analisar a influência das diferentes rachaduras que ocorrem no topo da tora, identificando qual delas é a mais importante na limitação do comprimento útil da peça serrada. 


\section{REVISÃO DE LITERATURA}

\subsection{Tensões de crescimento}

\subsubsection{Definições e Origem}

As tensões de crescimento ocorrem em várias espécies florestais. Estas são tensões mecânicas, geradas dentro de árvores vivas, tidas como uma característica natural da árvore durante seu crescimento, podendo ocorrer tanto em coniferas como em folhosas nos sentidos longitudinal, radial tangencial, sendo que no sentido longitudinal as tensões se apresentam na forma mais severa. Sua distribuição varia progressivamente de tração na periferia da árvore (casca), até máxima compressão no centro, conforme mostra a Figura 1( Wilkins, 1986).

Segundo Garcia (1992), que as tensões de crescimento são autogeradas no crescimento da árvore, que caracteristicamente existem dentro de um corpo sólido mesmo que esse não esteja sujeito a ações de tensões provocadas por forças externas atuantes. Essas tensões não dependem do peso da árvore e nem da variação do fluxo de seiva.

Essas tensões tem como função dar suporte a árvore, regulando a posição de sua copa em resposta às condições ambientais que the são impostas. As tensões de crescimento recebem esse nome por serem geradas durante a formação das células de madeira e por se acumularem ao longo do crescimento da árvore. 


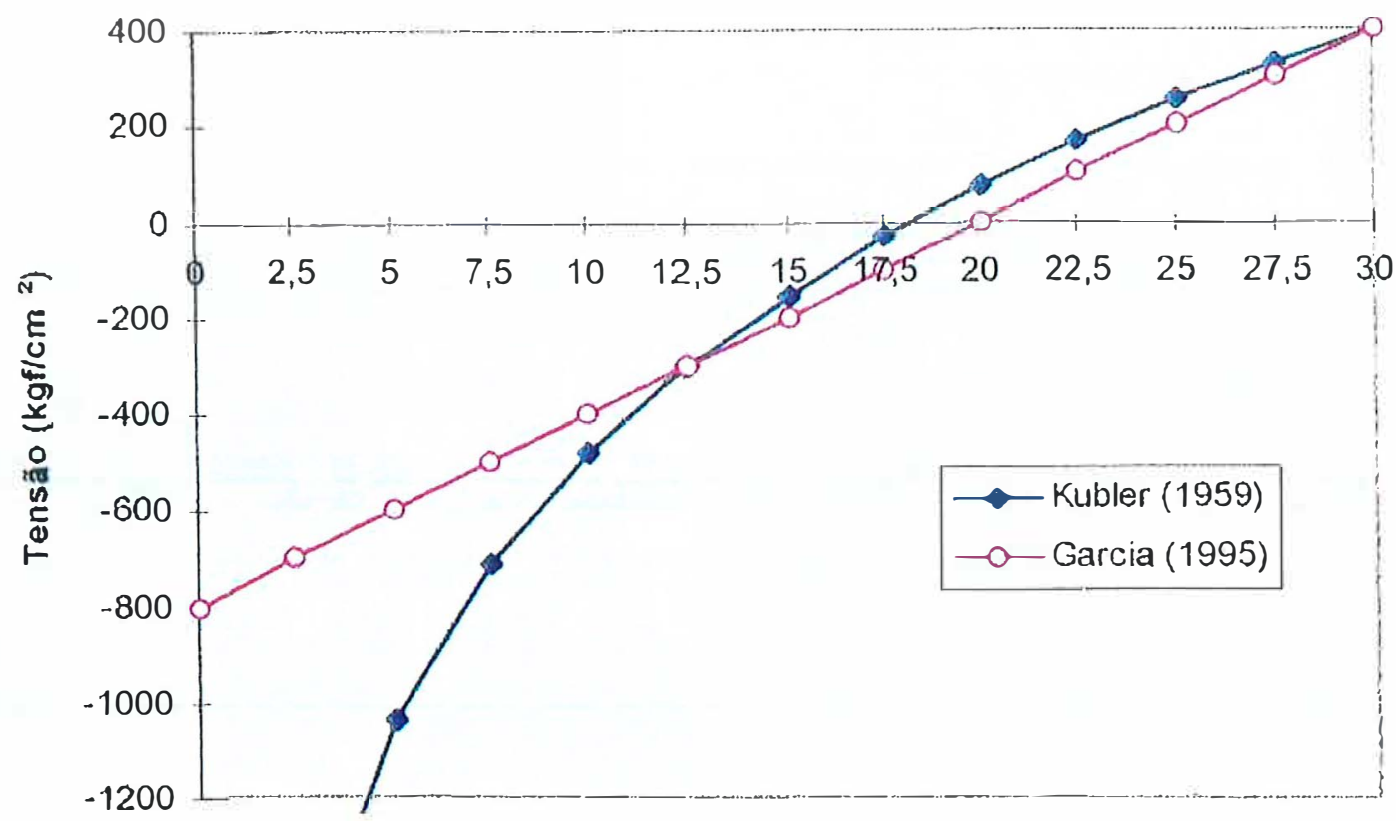

Raio da árvore

Figura 1 - Curvas de distribuição de tensões de crescimento ao longo do raio de uma árvore de $60 \mathrm{~cm}$, segundo os modelos de Kubler (1959) e Garcia (1995)

Fonte: Del Manezzi (1999).

Enquanto a árvore está em pé as tensões de crescimento estão em equilíbrio, no entanto quando é cortada, ocorre imediatamente deformações e rachaduras nos topos das toras, devido a mudança de estado de equilíbrio que vigorava durante o crescimento (Ferrand, 1983). Desse modo, a periferia da tora, sob tração, tende a encurtar após o corte e a zona central, sob compressão, sofre uma expansão empurrando a face do corte para o exterior, ocasionando as rachaduras de topo nas toras (Malan, 1979).

As espécies arbóreas de rápido crescimento em especial as do gênero Eucalyptus, apresentam propensão à rachaduras em toras e tábuas além de diversos tipos empenamentos durante o desdobro. Tais defeitos são provocados pelas tensões de crescimento.

Jacobs (1938), sugeriu que as tensões de crescimento são o 
resultado do encurtamento da nova camada de crescimento da madeira, e que esse fenômeno da mudança dimensional ocorre num determinado estágio de crescimento.

Segundo Vignote et al. (1996), as tensões de crescimento são devidas ao constante crescimento das células produzidas na região do câmbio e que no crescimento secundário tendem a expandir-se lateralmente e a contrair-se longitudinalmente, mas as células formadas nos anos anteriores, além de dificultarem este crescimento, geram um conjunto de tensões que seguem as direções clássicas da madeira. As magnitudes das tensões diferenciam dependendo da direção que se considera, assim, as tensões na direção axial é aproximadamente dez vezes superior às tensões transversais e dentro destas últimas, as tensões tangenciais são maiores do que as tensões radiais. A magnitude das tensões varia enormemente com a espécie, entre indivíduos de mesma espécie e dentro de um mesmo indivíduo, ao longo da altura da árvore e também ao longo do raio.

\subsection{Consequências das tensões de crescimento}

Segundo Nicholson (1973), o gênero Eucalyptus é o exemplo mais notável de madeira comercial, onde os niveis de tensões podem ser altos, apresentando como consequência a redução de madeira serrada de três modos sendo eles: rachaduras de topo de tora; distorção de toras e tábuas no desdobro e cerne quebradiço.

Esses defeitos estão relacionados com as tensões de crescimento, encontrado nas árvore jovens e adultas.

De acordo com Malan (1979), a presença de rachaduras de extremidade de tora provoca uma redução no rendimento de madeira serrada em função da perda no comprimento e largura das tábuas.

Galvão (1976), conclui que árvores de Eucalyptus globulus, com diâmetro inferior a $60 \mathrm{~cm}$, apresentaram tensões internas responsáveis pelo aparecimento de rachaduras nas peças desdobradas. Esse fato é devido a 
utilização de árvores novas.

Segundo Lima (2000), as principais consequências dos efeitos da tensão de crescimento manifestam-se através de deformações de crescimento, ocasionando a rachadura de extremidade de tora, sendo esta um importante indicador de seleção de árvores para serraria.

\subsubsection{Rachaduras de extremidades de tora}

A tendência da madeira serrada de eucalipto em apresentar rachaduras é uma característica específica do gênero. De acordo com Santini (1992) caracteriza-se rachaduras como as separações dos elementos constituintes da madeira no sentido longitudinal da grã.

As rachaduras de topo em toras e em peças processadas constituem, provavelmente, a maior fonte de perdas na utilização industrial da madeira de eucalipto. Segundo Waugh (1998), o gênero Eucalyptus é referido como madeira difícil de serrar pela maioria dos processadores, em razão dos altos niveis de tensões de crescimento, que juntamente às perdas durante o processo de secagem tornam difícil fabricar alguma coisa além de produtos de baixa qualidade para embalagem.

O que se observa na prática, no Brasil, pelo menos para o tipo e idade das florestas e o nível de tecnologia utilizada, é que a rachadura é o maior problema que as indústrias de processamento de madeira de eucalipto enfrentam. Deste modo, sua redução pode promover ganhos técnicos e econômicos de grande significado para a indústria baseada neste gênero (Assis, 2001).

Existem cinco tipos de rachaduras distintas que degradam a madeira. Estas segundo suas origens, podem ser descritas nos seguintes tipos: duas devidas às tensões de crescimento (rachaduras de extremidades e rachaduras laterais), uma do fenômeno de colapso, uma do processo de secagem e a última oriunda do próprio efeito da derrubada. Os vários tipos de rachaduras podem interagir entre $\mathrm{si}$, pelo fato das mesmas serem oriundas de 
um fenômeno complexo dependente do tempo para sua manifestação (Bariska, 1990).

Estudo realizado por Schacht \& Garcia (1997), concluíram que as primeiras rachaduras surgem até $04^{\circ}$ dia de armazenamento, podendo estar ocorrendo a manifestação combinada da tensão de crescimento, com a tensão de secagem, sendo associada a perda de água livre.

De acordo com Crespo (2000), as rachaduras que surgem no topo da tora são o resultado de um fenômeno complexo e como dependem do tempo para as suas manifestações, os vários tipos de rachaduras podem interagir entre si.

De acordo com Malan (1979), as rachaduras geralmente iniciamse imediatamente após o seccionamento da tora e normalmente atinge seu máximo depois de um período de 3 dias (Figura 2).

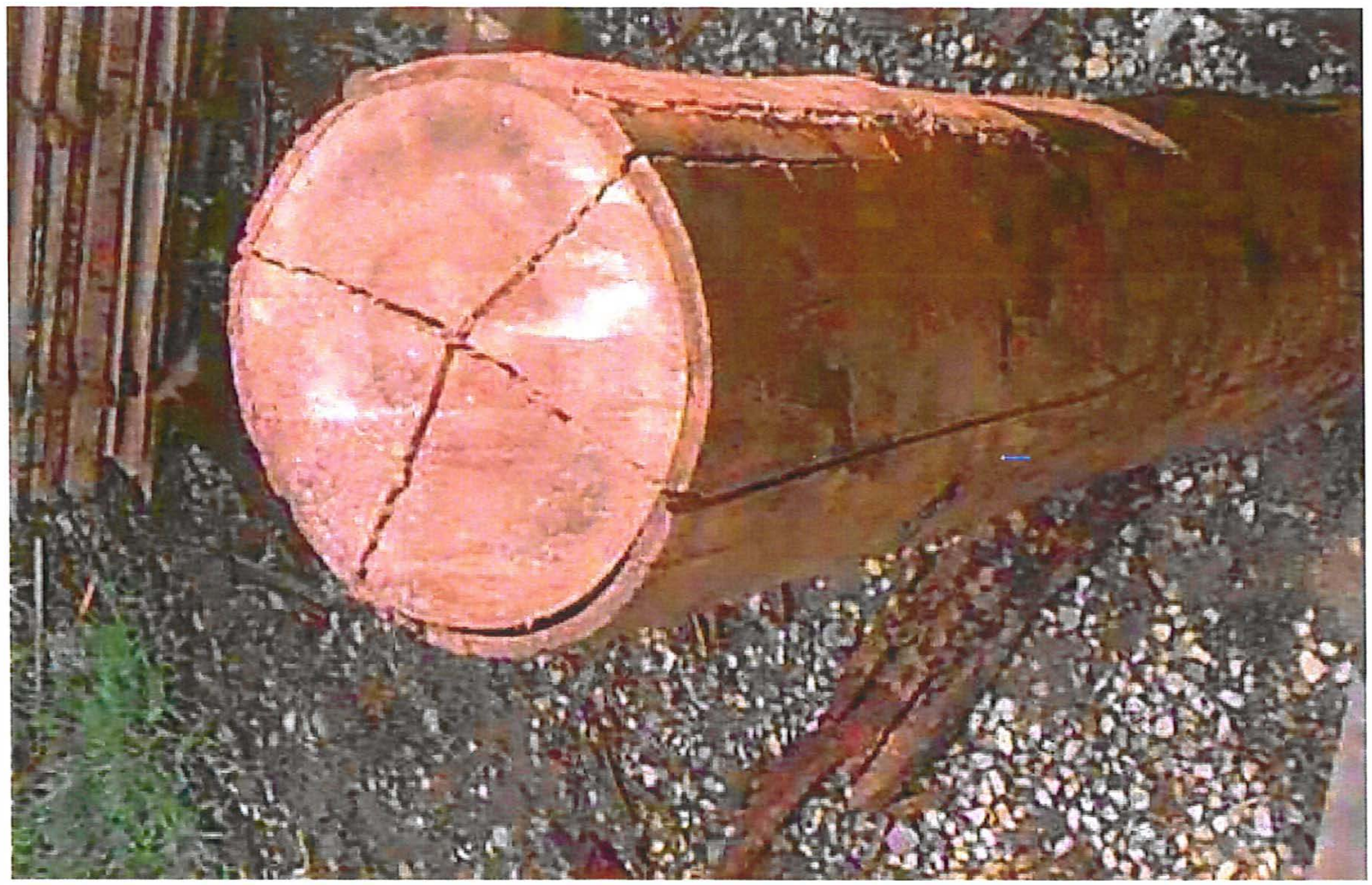

Figura 2 - Rachadura de extremidade de tora de Eucalyptus citriodora, logo após a derrubada e seccionamento da árvore 
O desenvolvimento de qualquer tipo de rachadura após a derrubada da árvore é característica hereditária da árvore, sendo estas dependentes do tempo. Devido a este fato, é de grande importância obter-se com um certo grau de exatidão uma técnica que permita predizer a extensão do máximo dano possível no produto final em tempo mínimo, como por exemplo na hora da queda da árvore (Bariska, 1990).

Algumas técnicas foram desenvolvidas com o objetivo de quantificar as rachaduras de extremidades de toras. Malan (1984), propôs um método no qual as rachaduras podem ser agrupadas em três classes de comprimento baseada na distância que elas alcançam, no plano da seção transversal, a partir da medula.

Já na metodologia de Conradie (1980), é feita apenas uma avaliação visual das rachaduras da seção transversal de corte, levando-se em conta também as rachaduras que não atingem a periferia.

Tais metodologias foram desenvolvidas com a finalidade de quantificar de forma indireta, as variações da tensão de crescimento e deveriam ser efetivas principalmente quando da necessidade de procederem-se avaliações rápidas e discriminatórias.

\subsubsection{Rachaduras em extremidades de tábuas}

No desdobro de madeira ocorre uma liberação de tensões fazendo com que a essa se deforme de acordo com as tensões a que estava submetida, dando origem as rachaduras em extremidades de tábua.

Alguns defeitos podem aparecer nas tábuas em função da sua orientação em relação aos planos radial e tangencial tais como o arqueamento, encanoamento, torcimento e encurvamento, que são empenamentos ou torções que aparecem nas peças serradas em virtude das tensões atuantes sobre elas.

De acordo com Panshim \& Zeeuw (1982), as tábuas mais próximas à medula apresentam maior intensidade de rachaduras. Isso ocorre porque as tensões de crescimento longitudinal não se encontram mais 
balanceadas pelas tensões das tábuas laterais que foram retiradas. Desta forma, as tensões em sentidos opostos que ocorrem na periferia dessas tábuas provocam seu rachamento, na região da medula, promovendo ainda o tracionamento no sentido perpendicular às fibras da medula, ocasionando a sua ruptura.

Conforme Santos et al ${ }^{1}$ (1998), as tensões longitudinais são em geral são as que mais causam defeitos na madeira, que apesar de apresentar tronco com tensões desuniformes no seu interior, normalmente não há deformação na madeira até que ela seja cortada no sentido transversal por ocasião do corte ou do desdobro. Neste instante, parte das forças que restringiam a mudança de dimensões das células é liberada e a madeira tende a comprimir nas regiões que estavam sob tração e a se expandir onde estavam sob compressão causando assim as rachaduras e empenamentos em peças serradas.

De acordo com Miranda \& Nahuz (1999), o efeito das tensões de crescimento pode ser observado nas toras após o abate das árvores e, principalmente, nas tábuas, durante e após desdobro em serraria, ocasionando diminuição do rendimento em madeira serrada, como mostra as Figuras 3a e $3 b$.

1 SANTOS, P.E.T.; SCANAVACA, L.; ADORNO, M.F.C. Apontamentos da Disciplina Propriedades Físicas e Mecânicas da Madeira - LCF-852. Escola Superior de Agricultura "Luiz de Queiroz". Piracicaba. (Năo publicado). 1998 


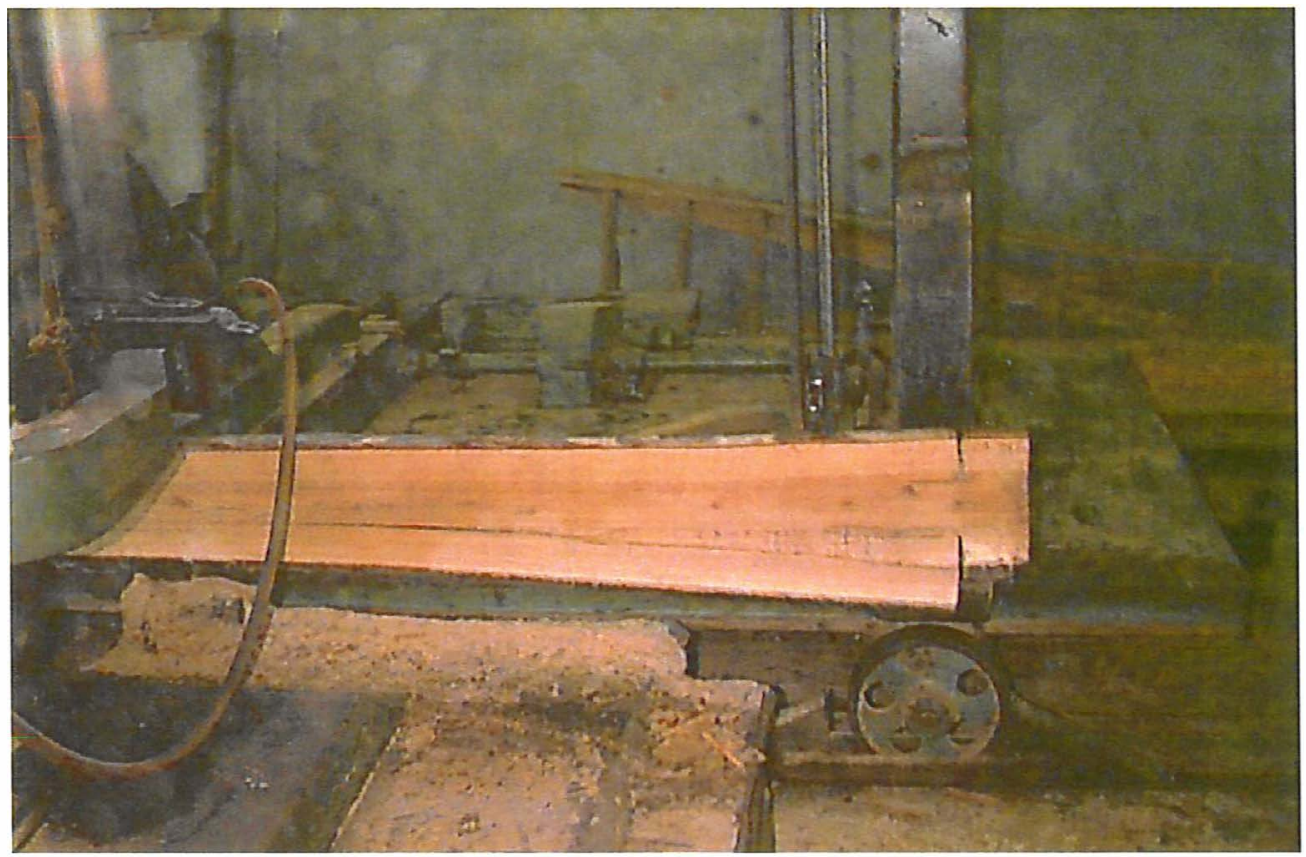

Figura 3a - Rachadura de extremidade de tábua de Eucalyptus citriodora durante desdobro

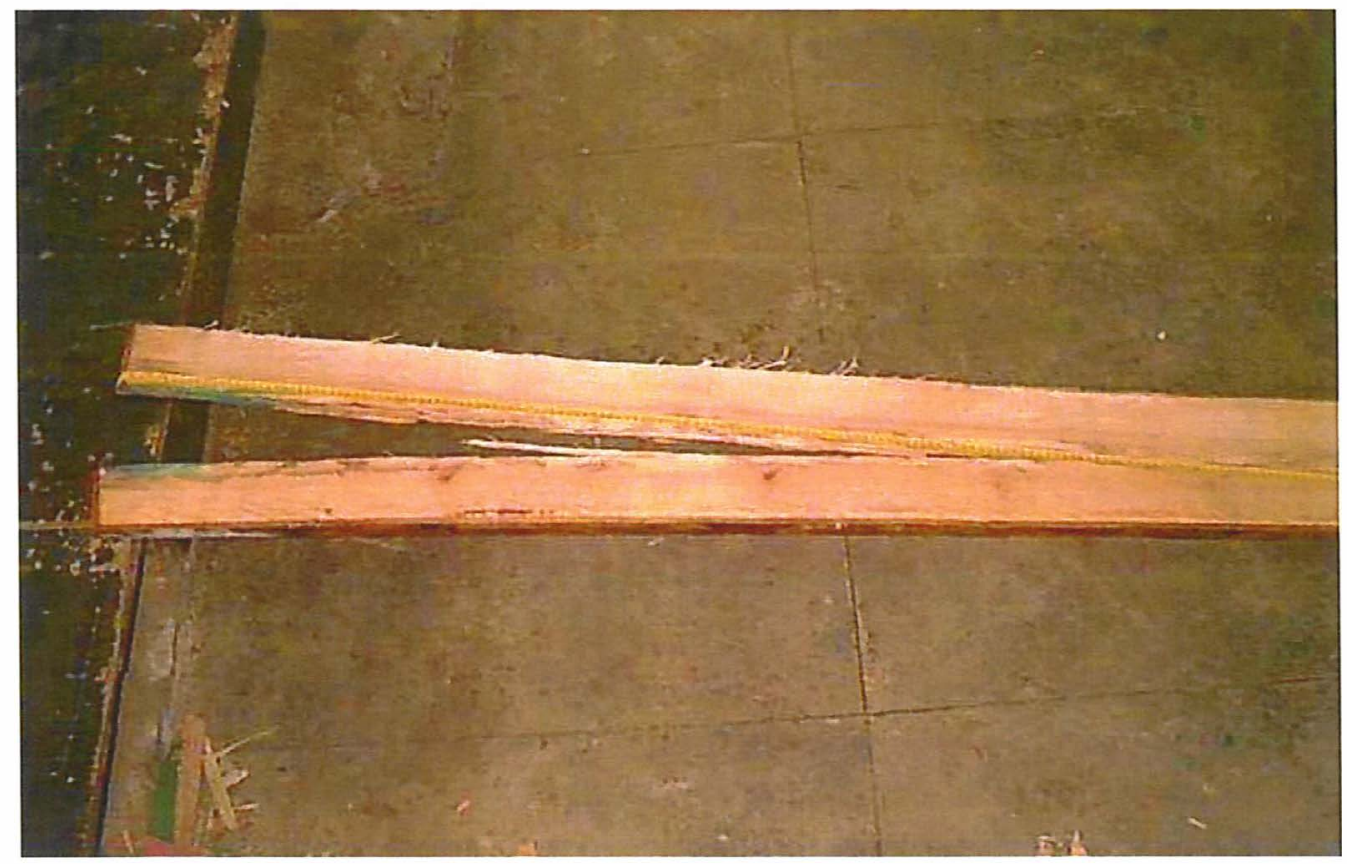

Figura 3b - Rachadura de extremidade de tábua de Eucalyptus citriodora devido ao desdobro e presença de tensões residuais na tora 
Por influência de outros tipos de tensões estas rachaduras devem aumentar acentuadamente no decorrer da semana. Podem ocorrer rachaduras adicionais e encurvamento longitudinal das peças serradas durante o processo de desdobro. Este fato se deve às tensões residuais ao longo da tora (Malan, 1979; Bariska, 1990).

\subsubsection{Cerne quebradiço}

Outra consequência das tensões de crescimento é o cerne quebradiço que é resultado de uma excessiva tensão de compressão que leva a madeira à ruptura por exceder a sua resistência intrínseca, limitando assim o uso da madeira de eucalipto (Nicholson, 1973).

Esse defeito faz com a madeira de eucalipto se torne quebradiça e portanto pouca atrativa, de baixa resistência afetando diretamente a qualidade e o rendimento do produto final.

Pesquisas realizadas por Chafe (1979), mostraram que o diâmetro exerce influência sobre a formação do cerne quebradiço. Sendo assim, quanto maior o diâmetro da árvore maiores serão as forças de compressão no centro da árvore causando a formação do cerne quebradiço.

\subsection{Técnicas de minimização de rachaduras}

Vários estudo já foram utilizados com a finalidade de minimizar os efeitos das tensões de crescimento, porém nenhuma delas até o momento obtiveram resultados satisfatórios na redução dos defeitos causados pelas tensões de crescimento.

De acordo com Rozas Mellado (1993), o ideal para a neutralização das tensões de crescimento seria a utilização de técnicas aplicadas nas árvores em pé, de tal forma de reduzir as rachaduras que ocorrem por ocasião da derrubada da árvore e sua transformação em toras.

As técnicas de minimização dos efeitos das tensões devem ser estudadas e incentivadas pelo fato do eucalipto apresentar problemas 
relacionados às etapas de processamento da madeira de eucalipto, principalmente a fase de desdobro. (Malan, 1995; Ponce, 1995).

\subsubsection{Anelamento}

O efeito do anelamento nas tensões de crescimento pode ser melhor entendido por ocasião do corte da árvore. A árvore em pé contém um alto nível de tensão longitudinal de crescimento em equilíbrio, é cortada transversalmente, a face do corte apresenta algumas deformações, ou seja, a parte externa próxima à casca, que estaria inicialmente sob tração, sofre um ligeiro encolhimento e a parte central próxima à medula, que estava sob compressão, um alongamento. A superfície da face do corte transversal que deveria estar plana, toma forma de uma calota e , a superfície do corte transversal aumenta sua área até o máximo da sua resistência à tração perpendicular aos raios, iniciando o aparecimento de uma fenda principal, ao longo do raio, passando pela medula. Dependendo da espécie outras rachaduras secundárias poderão aparecer (Pio, 1996).

Com a técnica do anelamento antes do corte transversal, ocorre eliminação de parte das tensões próximas à casca, diminuindo desta maneira a ação das forças responsáveis pela formação de rachadura de topo na face transversal após o corte. A liberação de parte das tensões internas de crescimento é limitada na extensão entre o anelamento e a face de corte.

Os efeitos das tensões de crescimento podem ser controladas de inúmeras maneiras, dentre elas o anelamento do tronco da árvore, de modo que está morra e continue em pé durante no mínimo seis meses. Esta técnica apresenta, porém, vários inconvenientes, sendo eles: riscos de queda, ataque de brocas (Ponce, 1995).

Pesquisas feitas por Barnacle \& Gottstein (1968), mostraram que rachadura de topo pode ser consideravelmente reduzida fazendo anelamento circunferencial em qualquer posição transversal ao tronco. Esta técnica pode 
ser também aplicada antes da árvore ser derrubada, fazendo o anelamento acima da posição onde será feito o corte para derrubada da árvore.

Essa técnica embora pareça ser útil para redução de rachaduras de topo em toras, pode ocasionar alguns problemas. Estes estão relacionados com o tempo necessário para se conseguir um efeito significativo no grau de rachadura de topo (De Villiers, 1973)

Segundo Kubler (1987), cada anelamento cria um novo tronco parcial, porém, inicia-se uma nova tensão elástica tangencial no ou ao anelamento. Por esta razão é inútil fazer anelamentos com profundidades maiores que $1 / 3$ do diâmetro do tronco.

Conradie (1980), testou o anelamento com três profundidades de corte e também três distâncias entre $\mathrm{O}$ anelamento e o corte transversal, chegando à conclusão de que os valores das rachaduras diminuíram com o aumento da profundidade e com a distância do anelamento para o topo da tora.

Aguiar (1986), ao analisar toras que receberam o anelamento antes do corte transversal, observou que este não só diminuiu consideravelmente as rachaduras de topo como também diminuiu significativamente as tensões de crescimento residuais nas toras de Eucalyptus grandis. O mesmo autor salienta que quando é utilizada essa técnica de anelamento antes do corte transversal ocorre a eliminação de parte de tensões próximas à casca, diminuindo assim a ação das forças responsáveis pela formação de rachadura na face transversal após o corte, sendo que a liberação de parte das tensões internas de crescimento é limitada na extensão entre o anelamento e a face de corte.

Rocha (2002), ao trabalhar com técnicas de minimização dos efeitos das tensões de crescimento verificou que o anelamento da árvore ou a aplicação de herbicida, 30 dias antes da derrubada da árvore mostrou-se apropriado para a redução das rachaduras de extremidade de tábua. 


\subsubsection{Corte em Bisel}

Pesquisas desenvolvidas por Tantichaiboriboon

(1977), mostraram que cortes oblíquos ou inclinados, feitos em ângulos menores que $90^{\circ}$ com o eixo do tronco, reduzem altas tensões próximas à medula. Apesar dos inconvenientes operacionais, Mattheck \& Walther, 1991, provaram matematicamente que os cortes inclinados reduzem as rachaduras, em árvores que serão abatidas. Porém, essa técnica foi desenvolvida para minimizar o efeito das tensões de crescimento durante o abate da árvore.

Testes são necessários para provar se os rendimentos de troncos serrados aumentam com estas técnicas envolvidas (ranhuras circunferencial e cortes oblíquos) e com os custos do tratamento (Malan, 1979).

Assim como o anelamento essa técnica foi desenvolvida para ser aplicada na árvore em pé.

\subsubsection{Proteção do topo da tora com Piche}

Testes de campo realizados por Pandey (2000), indicaram, na Índia, em 3 localidades diferentes, Yamuna Nagar, Seonsar em Haryana e Phillaur em Punjab, que toras verdes de Eucalyptus tereticornis revestidas nas extremidades com piche, não desenvolveram rachaduras mensuráveis em até 6 meses de armazenamento na sombra. Assim, o autor conclui que essa técnica é bastante eficiente quanto a prevenção de rachadura de topo de tora, e que o tempo de armazenamento foi estendido.

\subsection{Desdobro}

No processamento de madeiras com elevadas tensões de crescimento como as do gênero Eucalyptus, deve-se aplicar técnicas de desdobro apropriadas já que este é um fator determinante no bom aproveitamento da madeira de tais espécies.

Devido as várias características apresentadas pela madeira de eucalipto durante a fase de processamento ocorre uma série de defeitos, por 
isso esta merece uma atenção especial desde a obtenção da tora até sua secagem, de tal forma que a manifestação desses defeitos seja minimizada (Rocha, 2000).

O desdobro consiste em converter as toras de madeira em tábuas, pranchas e vigas de secções retangulares ou quadradas nas mais variadas bitolas e medidas (Barchet, 2001).

Segundo Andrade (1961), o desdobro de árvores com idades mais avançadas, são de extrema importância para o êxito da utilização do eucalipto. $\mathrm{Na}$ Austrália esta prática é realizada com árvores de idades superiores a 25 anos para vigamentos, construções e dormentes. Já no Brasil, Galvão (1976), recomenda-se a utilização de árvores de pelo menos 30 anos.

O mesmo autor salienta que para se obter sucesso com a utilização de eucalipto como material de serraria, deve-se utilizar espécies adequadas, idade conveniente, no qual as toras devem ser desdobradas de acordo com métodos que considere as características de sua madeira.

No Brasil, há a necessidade de desenvolvimento e mesmo de adaptações dos sistemas de serrarias tradicionais, para que as espécies de rápido crescimento possam ser desdobradas com rendimento satisfatório, principalmente com relação às tensões de crescimento. Equipamentos adequados e técnicas próprias de desdobro, são sem dúvida alguma, um fator muito importante no bom aproveitamento das toras produzidas por espécie de rápido crescimento, como é o caso do eucalipto. (Barchet, 2001).

Diversas técnicas de desdobro têm sido utilizadas no processamento de madeira de eucalipto que apresentam vantagens e desvantagens. Para se obter sucesso no desdobro é necessário que se estabeleça uma combinação entre as espécies, as idades, os diâmetros e as origens das espécies e árvores devendo-se evitar fazer uma simples comparação de rendimentos de madeira serrada. Entretanto, pode-se inferir quais das técnicas utilizadas produzem menor quantidade de defeitos durante $o$ processo de desdobro e, também, após a secagem, sendo que esta última 
avaliação se faz necessária, uma vez que as técnicas de desdobro produzem tábuas que apresentarão defeitos no processo de secagem e que não poderão ser totalmente utilizadas. Portanto, durante a seleção da melhor técnica deverá ser escolhida a que a causar menores problemas, do ponto de vista da secagem e das tensões de crescimento (Del Menezzi \& Nahuz, 1998).

Dentre as técnicas de corte utilizadas para o desdobro de toras de eucalipto pode-se citar: corte tangencial e radial.

O corte tangencial consiste na obtenção de peças tangenciais às camadas de crescimento. Segundo Pandey et al. (1984), esta técnica é bastante utilizada para outras espécies, mas quando é aplicada para madeira de eucalipto, apresenta alguns problemas. Um destes problemas é que a parte interna da tábua que está sob compressão, com o corte, tende alongar-se, por outro lado a parte exterior, sob tração, tende a encurtar. Sendo assim, a tábua retirada no sentido tangencial que seria reta, torna-se encurvada para fora da tora. Os mesmos autores salientam também que as peças assim obtidas apresentam diversos problemas durante processos subsequentes, tais como: colapso, empenamento, fendas de superfície e torcimento.

A técnica de cortes radiais, consiste na execução de cortes radialmente às camadas de crescimento, objetivando-se a obtenção do maior número possível de tábuas com faces no mesmo plano dos raios (Bootle, 1983 apud Del Menezzi \& Nahuz, 1998). Segundo o mesmo autor, as vantagens de peças radiais são: melhor aparência à madeira de folhosas, em função da disposição dos raios e da grã; menor contração no sentido da largura da tábua, proporcionando menor movimentação em serviço; as bolsas de resina, comuns em eucalipto, apresentam-se nas tábuas radiais com linhas finas, sendo aceitáveis quanto à aparência; tábuas radiais geralmente são menos suscetíveis ao encanoamento e ao fendilhamento; tábuas radiais de eucalipto que são suscetíveis ao colapso durante a secagem, podem ser mais facilmente recondicionadas. 
De acordo com Galvão (1976b), no desdobro de toras de eucalipto, deve-se procurar obter a maior quantidade possivel de madeira radial, que tem menor possibilidade de apresentar defeitos de secagem, por se movimentar menos. Entretanto é uma prática que tem sido sistematicamente ignorada em nosso meio.

Segundo o autor, alega-se que os métodos de desdobro para obtenção da madeira radial são mais caros e com menor produção e rendimento de madeira serrada em relação ao método de cortes paralelos, que originam peças tangenciais. Contudo, na Austrália, os métodos radiais são os indicados e efetivamente utilizados no desdobro de madeira de eucalipto, onde o menor rendimento e produção são amplamente compensados por uma redução de defeitos das peças obtidas e seu melhor comportamento em uso.

Garcia (1997), sugere que para serrar toras com altos niveis de tensão de crescimento, o que acontece quando se trabalha com Eucalyptus, pode-se usar uma serra dupla seguida de uma serra múltipla para balancear a liberação das tensões de crescimento. Esse método de desdobro não evita a curvatura da madeira, porém permite que os encurtamentos nas peças serradas sejam preditos com suficiente exatidão.

Segundo Nicholson (1973), altos níveis de tensão de crescimento provocam deformações em tábuas, e para obter-se um produto com melhor qualidade é preciso resserrar a peça.

As tensões de crescimento são sérios fenômenos que afetam a qualidade da madeira, as dimensões, o produto e o rendimento em madeira serrada (Malan, 1979).

Lisboa (1993), verificou que durante o desdobro da tora, as rachaduras tendem a aumentar, principalmente se as técnicas de corte que favorecem o alívio simétrico e homogêneo de tensões não forem utilizadas. Tal cuidado deve ser tomado para minimizar a ocorrência de empenamentos de pranchões e tábuas, consequentes do encurvamento da própria tora, frequentemente observado durante a operação de desdobro assimétrico. 
Para obtenção de bons rendimentos em madeira serrada e de boa qualidade deve se adotar uma técnica de desdobro que compatibilize a matériaprima com os equipamentos existentes na serraria. Porém, há uma técnica de desdobro mais apropriada para cada "lay out", porque em cada um deles a manifestação das tensões de crescimento, se dará de uma forma diferente (Garcia, 1995).

Garcia (1988), observou a existência de um gradiente de qualidade no sentido medula-casca e concluem que se esse gradiente se mantiver constante ao longo da altura da árvore, o desdobro convencional, de cortes paralelos à medula, produzirá peças serradas de pior qualidade. Esse problema não existe no desdobro de toras cilíndricas.

Segundo Ponce (1995), a solução mais simples e adequada tanto para pequenas como grandes indústrias é o de cortes simultâneos de duas costaneiras, por meio de serras duplas. Em seguida o bloco restante deve ser desdobrado em uma serra múltipla seguido de vários cortes simultâneos. Deste modo têm-se obtido bons resultados, com rendimentos próximos de $50 \%$ em madeira serrada para toras de 15 a $30 \mathrm{~cm}$ de diâmetro.

Entretanto, Garcia (1997), serrando toras de Eucalyptus urophylla com serra de fita dupla seguida de uma serra múltipla com o objetivo de aliviar as tensões de crescimento de forma balanceada, verificou que ocorre uma redução do comprimento das peças serradas, devido as rachaduras de extremidade, sendo muito comum ter-se uma perda de $23 \mathrm{~cm}$ no comprimento total da peça.

Para reduzir essa perda o mesmo autor salienta que deve-se evitar trabalhar com toras de pequenos comprimentos, já que cada corte transversal efetuado no tronco da árvore produzirá duas extremidades livres, portanto sujeitas a rachaduras. Caso haja impossibilidade de desdobrarem-se toras longas, recomenda-se que os cortes transversais sejam feitos imediatamente antes do desdobro. 


\section{MATERIAL E MÉTODOS}

\subsection{Matéria Prima}

Foram obtidas 24 árvores de Eucalyptus citriodora Hook, oriundas de uma plantio (sementes) de 23 anos de idade da área experimental do grupo florestal Monte Olimpo, localizada no compus da ESALQ/USP. O espaçamento utilizado no plantio das árvores de Eucalyptus citriodora foi de $3 \times 2 \mathrm{~m}$. O talhão no qual as árvores foram plantadas sofreu um desbaste em 1996.

As árvores utilizadas no experimento estavam selecionadas para desbaste a ser realizado em 2003. Dentre essas árvores buscou-se indivíduos com troncos cilíndricos e menor incidência de galhos. O corte transversal de derrubada foi realizado perpendicularmente ao eixo transversal do fuste, a uma altura de aproximadamente $20 \mathrm{~cm}$ do solo.

Após a queda, as árvores foram arrastadas para fora do talhão e aplicadas as técnicas de prevenção de rachaduras. Cada árvore forneceu em média 3 toras de $2 \mathrm{~m}$ de comprimento, totalizando 72 toras. Essas 72 toras foram divididas em três lotes a serem desdobrados após diferentes tempos de armazenamento.

\subsection{Tratamentos aplicados}

\subsubsection{Classe diamétrica}

Foram derrubadas árvores para a obtenção de toras em duas classes diamétricas, com 2 metros de comprimento. A primeira de média $18 \mathrm{~cm}$ (no intervalo de [15.5 a 20.5] cm), e a segunda de média $23 \mathrm{~cm}$ (no intervalo de $(20.5$ a 25.5$] \mathrm{cm})$. 


\subsubsection{Técnicas de prevenção ou minimização de rachaduras}

No presente trabalho foram utilizadas toras provenientes de diferentes árvores de Eucalyptus citriodora para testarem-se três técnicas de prevenção ou minimização de rachaduras de extremidades de tora, sendo elas: anelamento, corte em bisel (chanfro), e aplicação de piche no topo da tora. A testemunha foi a técnica normalmente usada, de cortes de seccionamento da árvore em toras perpendiculares ao seu eixo e sem nenhum tratamento de proteção do topo da tora. Foram avaliadas as rachaduras de extremidades de tora, sua velocidade de propagação no tempo e sua real influência nas rachaduras de extremidades de tábua.

\subsubsection{Anelamento}

O anelamento foi executado nas duas extremidades das toras, adotando-se a metodologia utilizada por Barnacle \& Gottstein (1968). O anelamento foi efetuado com a própria motosserra, aprofundando-se o seu sabre até cerca de $1 / 3$ do raio da tora, a uma distância de $10 \mathrm{~cm}$ do ponto de seccionamento, de acordo com a Figura 4.
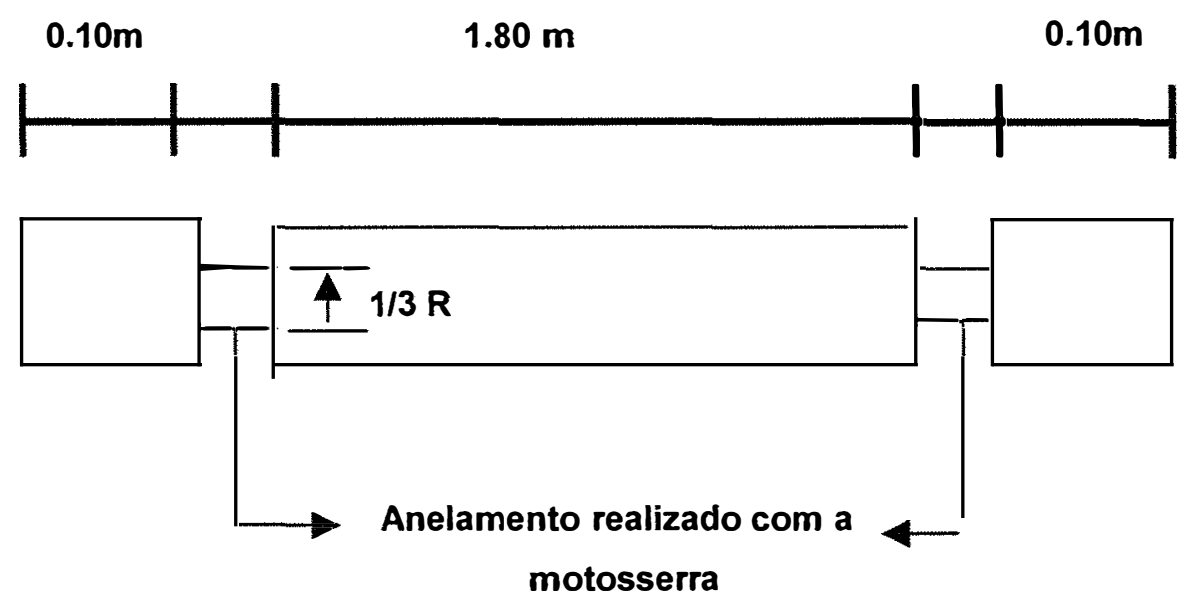

Figura 4 - Aspecto da tora após o anelamento 
Primeiramente foi feito $\mathrm{o}$ anelamento como descrito acima, e posteriormente o seccionamento da tora anelada. A Figura 5 , mostra a simulação de como foi feito o anelamento da tora.

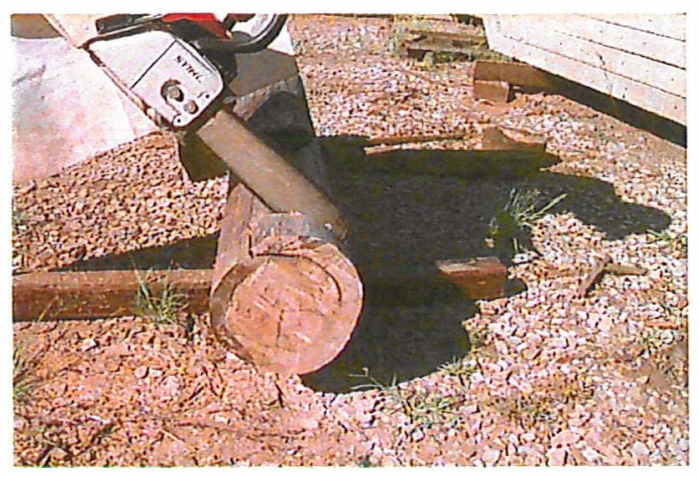

(a)

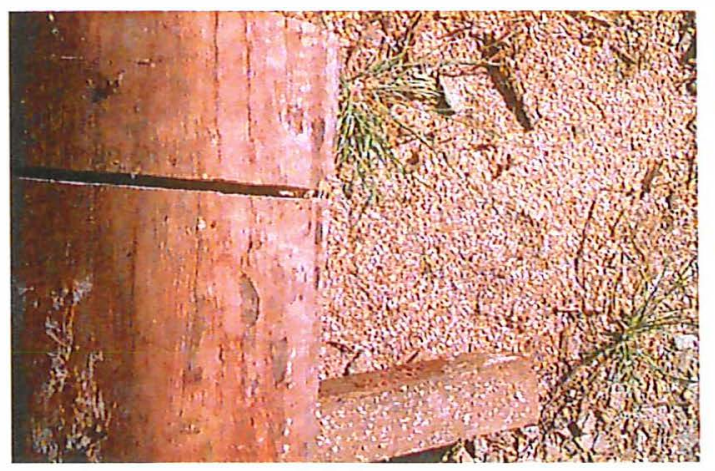

(c)

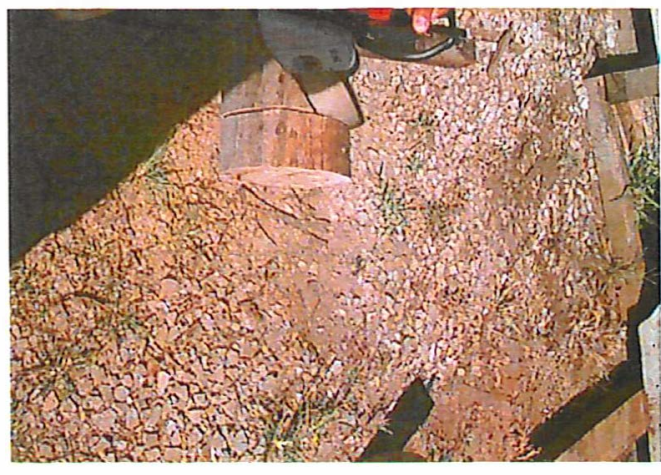

(b)

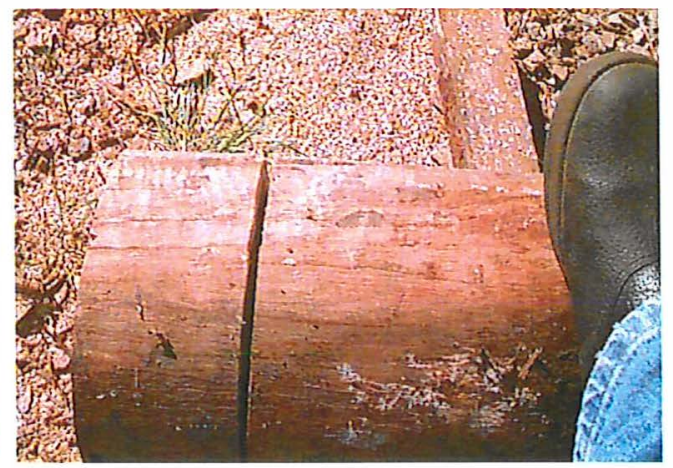

(d)

Figura 5 - Ilustração das etapas de anelamento das toras

Dessa forma, as toras ficaram com um comprimento útil, $20 \mathrm{~cm}$ mais curto que o comprimento da testemunha, como pode ser visto na Figura 4.

\subsubsection{Chanfro}

Essa técnica consiste em cortes feitos nas duas extremidades da tora com um ângulo de $60^{\circ} \mathrm{em}$ relação ao eixo da tora. A direção do corte foi determinada utilizando-se um gabarito construído de acordo com o ângulo especificado acima, como mostra a Figura 6 . 


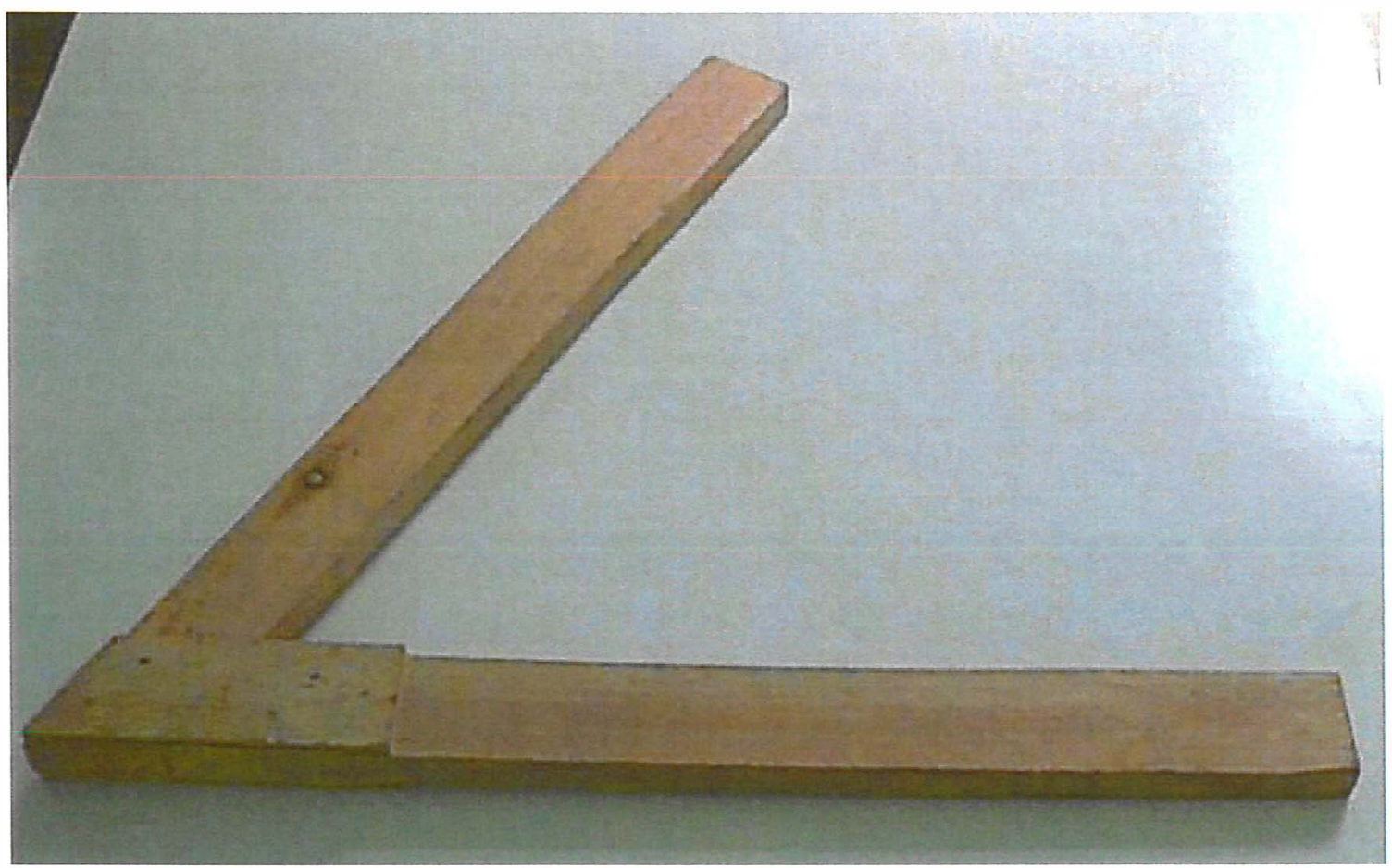

Figura 6 - Gabarito utilizado para realização do corte em chanfro com ângulo de $60^{\circ}$

Esse gabarito foi construído na serraria da ESALQ/USP utilizando uma esquadrejadeira de bancada.

Os cortes em chanfro foram realizados com a motosserra, antes do seccionamento do tronco da árvore, logo após a sua derrubada. Na Figura 7 observa-se a simulação do corte em chanfro. 


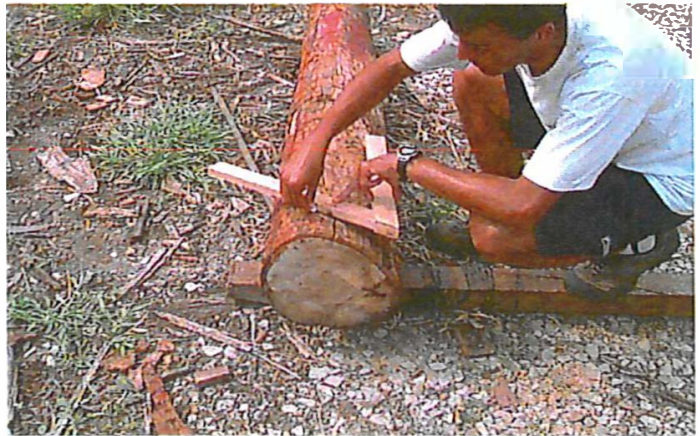

(a)

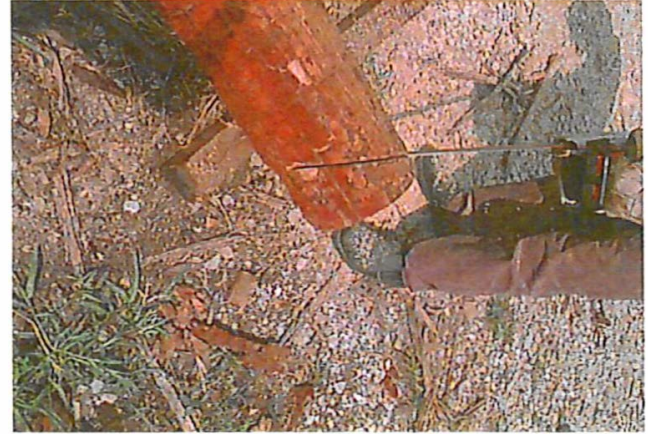

(b)

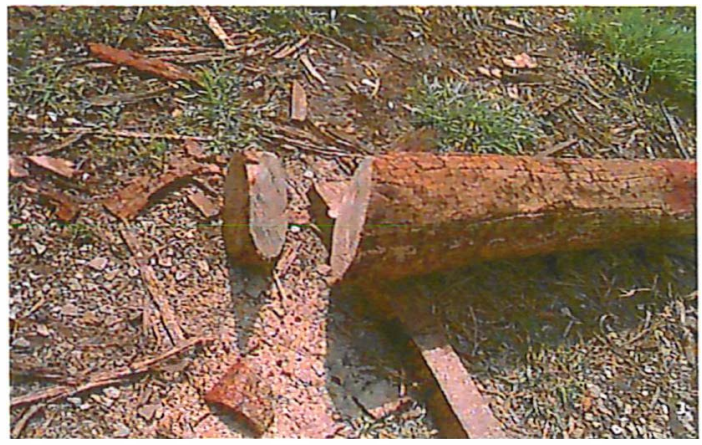

(c)

Figura 7 - Simulação do corte da tora em chanfro

\subsubsection{Proteção do topo da tora com Piche}

Essa técnica consistiu na aplicação de piche quente nas duas extremidades da tora, com pincel. A aplicação foi realizada imediatamente após o corte transversal da tora, em seus topos, conforme ilustra a Figura 8. 


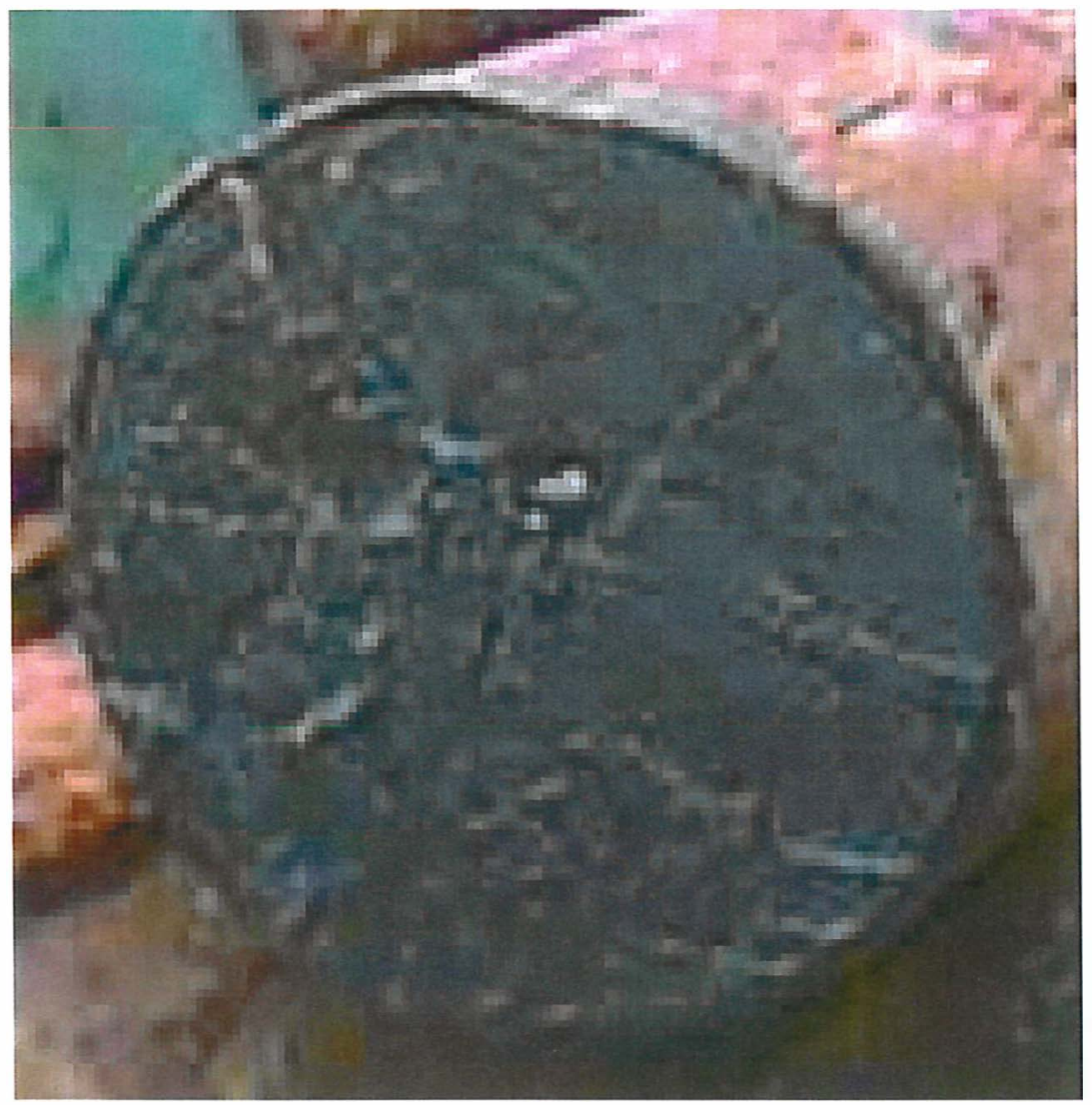

Figura 8 - Aspecto da tora após vedação do topo da tora com piche

\subsubsection{Tempos de armazenamento}

Os tempos de armazenamento utilizados na pesquisa chamados 1,2 e 3 representaram os tempos de armazenamento 7, 14 e 21 dias respectivamente, nos quais foram distribuídos os tratamentos testados na pesquisa. Cada lote continha 24 toras, perfazendo um total de 72 toras. Os três lotes foram avaliados de acordo com o tempo de armazenamento que cada um representava através da medição de rachadura de topo de tora antes do desdobro e medição da rachadura de extremidade de tábua após o desdobro. 


\subsection{Estudo da taxa de propagação das rachaduras, no sentido radial e longitudinal da tora}

A técnica utilizada para verificação da propagação das rachaduras ao longo do tempo de armazenamento da tora foi a de aplicação de tintas nas aberturas das rachaduras do topo da tora, em pelo menos uma de suas extremidades, nos tempos 7, 14 e 21 dias. Em cada um desses tempos foi aplicada uma tinta de cor diferente para permitir a quantificação da profundidade alcançada pela rachadura, num determinado tempo, em relação à rachadura verificada no tempo anterior. Foram utilizadas tintas látex à base de água, de baixa viscosidade, pois as mesmas são de mais fácil e rápida penetração nas rachaduras.

Após a realização do anelamento e chanfro nas extremidades das toras, essas foram colocadas na posição vertical. Em seguida foi despejada a tinta, da cor que caracterizava o tempo de armazenamento da tora, bem diluída, nas rachaduras de topo, utilizando uma seringa de $100 \mathrm{ml}$ como mostrado na Figura 9, de tal forma a permitir que a tinta alcançasse toda a extensão do comprimento longitudinal da rachadura. $\mathrm{Na}$ técnica do piche a tinta foi despejada antes da aplicação do piche. As tintas de cores vermelha, branca, verde e amarela foram aplicadas, respectivamente, nos tempos 7, 14 e 21 dias de armazenamento das toras. 


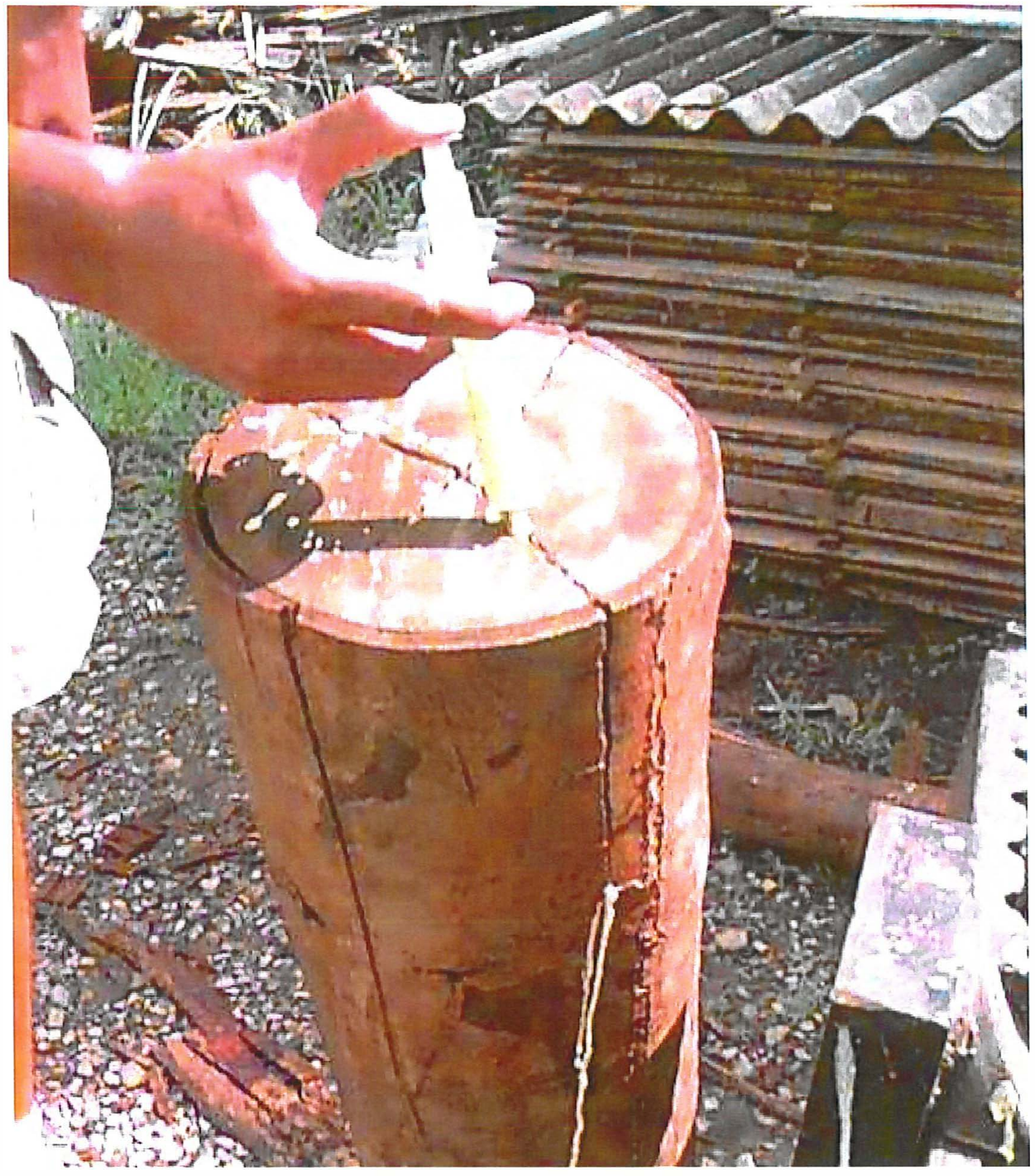

Figura 9 - Aplicação de tinta em uma das extremidades da tora 


\subsubsection{Medição das rachaduras de topo de toras}

As medições foram feitas utilizando uma régua para a medição tanto do comprimento quanto da largura de cada rachadura do topo da tora em todos os tempos citados anteriormente.

A metodologia empregada foi a proposta por Lima, 2000, que consiste na medição direta de cada rachadura. $O$ cálculo do indice de rachadura foi feito de acordo com a eq. 1 .

$$
I R=200\left[\frac{\sum_{i=1}^{n} a_{i} C_{i}}{\pi D^{2}}\right]
$$

Onde:

$\mathrm{IR}=$ indice de rachadura $(\%)$;

$a_{i}=$ abertura máxima da rachadura $(\mathrm{cm})$;

$\mathrm{C}_{\mathrm{i}}=$ comprimento da rachadura; $i(i=1$, n) $(\mathrm{cm})$;

$D=$ diâmetro médio da seção de corte $(\mathrm{cm})$;

$\mathrm{n}=$ número de rachaduras medidas na seção transversal da tora

\subsection{Desdobro}

O desdobro da madeira foi realizado na serraria do Departamento de Ciências Florestais da ESALQ/USP, em Piracicaba-SP, em uma serra de fita simples, de diâmetro de volante igual a $110 \mathrm{~mm}$, carro porta tora tipo semipesado, com velocidade de avanço de aproximadamente $7,5 \mathrm{~m} /$ minuto, espessura de corte de $3,0 \mathrm{~mm}$, largura da lâmina de $12 \mathrm{~cm}$ e comprimento da lâmina de 7,5 m.

Foi utilizado o método de cortes tangenciais onde, primeiramente, retirou-se a costaneira $\mathrm{C}$ e mais duas tábuas. Em seguida deu-se um giro de $180^{\circ}$ na tora e retirou-se a outra costaneira, e efetuaram-se os demais cortes tangenciais sucessivos visando a obtenção de tábuas com espessura de 2,5 $\mathrm{cm}$, como mostra a Figura 10. 
Durante o desdobro, procedeu-se a identificação de cada tábua produzida, com a finalidade de estudá-la. Foram medidos os seguintes parâmetros: dimensões das tábuas, comprimento das rachaduras de extremidades tábuas.

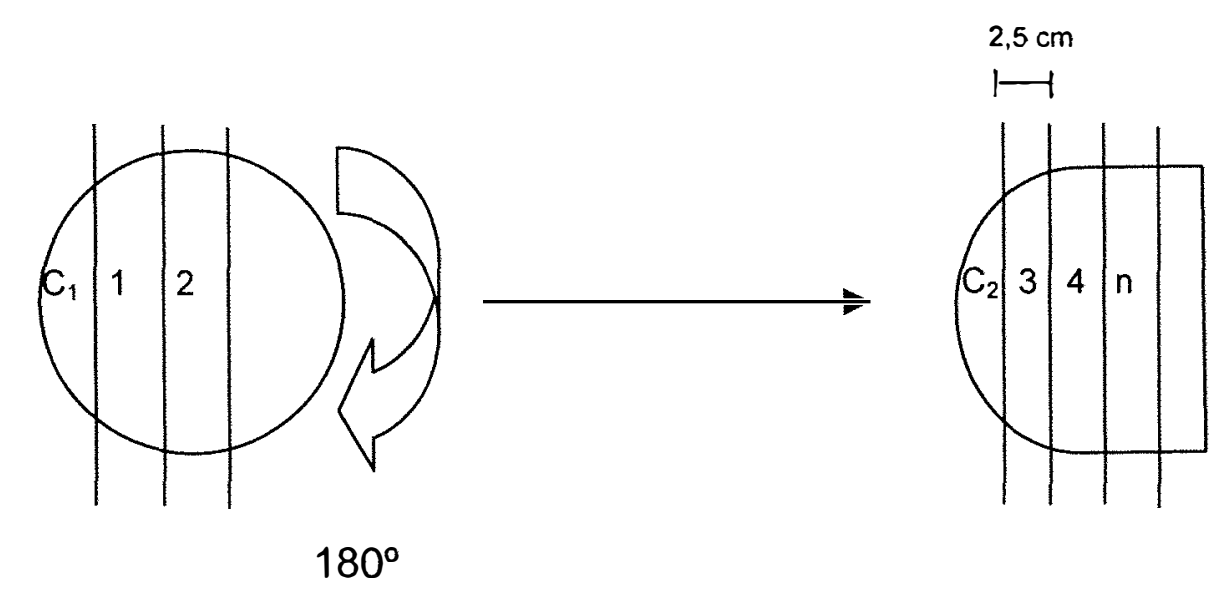

Figura 10 - Método de desdobro visando tábuas tangenciais, utilizando-se serra de fita simples

\subsubsection{Medição das rachaduras de extremidade de tábua}

Foi medido o comprimento da maior rachadura em cada extremidade da tábua, utilizando-se uma trena comum, logo após o desdobro. $\mathrm{O}$ índice de rachaduras de extremidade de tábua foi calculado de acordo com a eq. (2) proposta por Schacht \& Garcia (1998), cujas variáveis foram obtidas de acordo com a Figura 11.

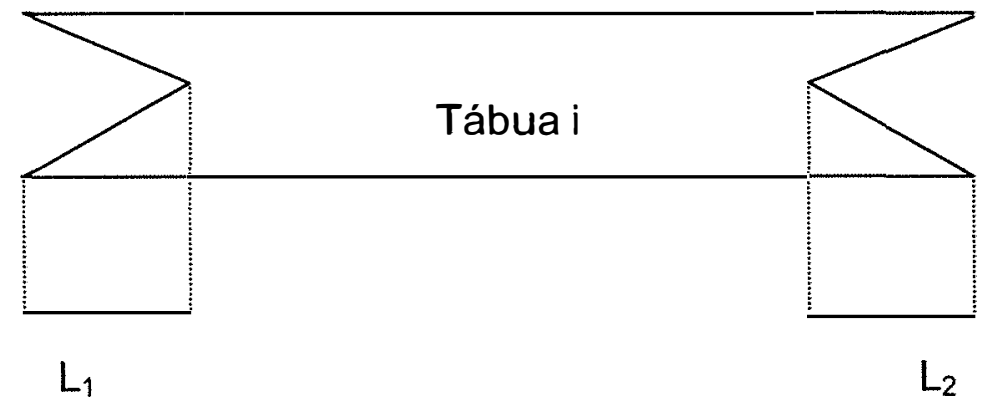

Figura 11 - Rachaduras de extremidades de tábua 


$$
R_{t}=\frac{\sum_{i=1}^{n t}\left(l_{1}+l_{2}\right)}{n t}
$$

Onde:

$\mathrm{R}_{\mathrm{t}}=$ rachadura de extremidade de tábua $(\mathrm{cm})$;

$\mathrm{I}_{1}$ e $I_{2}=$ comprimento das rachaduras das extremidades 1 e 2 , respectivamente; $\mathrm{nt}=$ número de tábuas obtidas da toras.

\subsection{Delineamento Experimental e Análise Estatística}

Para o experimento desenvolvido no presente estudo foi adotado um delineamento inteiramente casualizado com arranjo fatorial do tipo $3 \times 2 \times 4$ para os tratamentos (24), cujos fatores foram o tempo de armazenamento (3), a classe diamétrica (2) e a técnica de prevenção de rachaduras de topo (4). Adotou-se 3 repetições por tratamento, totalizando 72 toras. Foram feitas análises de variância para a verificação de possiveis diferenças entre os fatores. Os dados foram transformados por $\log \sqrt{x+0,5}$, pelo fato dos mesmos não apresentarem distribuição normal. A significância entre os tratamentos foi testada através do teste F. Para as comparações entre as médias das técnicas foi utilizado o teste de Tukey ao nivel de $5 \%$ de probabilidade. 


\section{RESULTADOS E DISCUSSÃO}

\subsection{Análise estatística para o índice de rachadura de tora (IR)}

$\mathrm{Na}$ Tabela 1 encontram-se os resultados da análise estatística realizada para o índice de rachadura de extremidade de tora para a verificação da existência de diferenças significativas para os fatores e interação entre eles. Observa-se na Tabela 1 que não existem diferenças significativas entre as classes de diâmetro e entre os tempos de armazenamento, mas existem diferenças significativas entre as técnicas de prevenção. Constatou-se que não houve interação significativa entre os fatores.

Tabela 1. Análise de variância para variável IR (\%)

\begin{tabular}{lccc}
\hline Causa de Variação & GL & $\mathrm{F}$ & $\mathrm{P}>\mathrm{F}$ \\
\hline Classe de diâmetro (1) & 1 & 1.063 & $0.30 \mathrm{~ns}$ \\
Tempo de armazenamento (2) & 2 & 2.509 & $0.91 \mathrm{~ns}$ \\
Técnica de prevenção (3) & 3 & 2.893 & 0.04 \\
$1 \times 2$ & 2 & 0.550 & $0.58 \mathrm{~ns}$ \\
$1 \times 3$ & 3 & 0.636 & $0.59 \mathrm{~ns}$ \\
$2 \times 3$ & 6 & 0.622 & $0.71 \mathrm{~ns}$ \\
$1 \times 2 \times 3$ & 6 & 0.461 & $0.83 \mathrm{~ns}$ \\
(Tratamento) & $(23)$ & & \\
Resíduos & 48 & & \\
Total & 71 & & \\
\hline
\end{tabular}


Os valores obtidos da comparação de médias do IR (\%), revelam que as técnicas de corte Anelamento, Piche e Testemunha não diferem entre si. Entretanto a técnica Anelamento diferiu significativamente da técnica do corte de Chanfro. A Figura 12 resume essa discussão mostrando que o anelamento foi a técnica que apresentou menor valor médio de $\mathrm{IR}(\%)$ em relação as demais técnicas. Por outro lado constatou-se que o chanfro foi a técnica que apresentou maior IR (\%).

Tabela 2. Comparação entre as médias das diferentes técnicas de prevenção pelo teste de Tukey

\begin{tabular}{cccc}
\hline \multicolumn{3}{c}{ TÉCNICAS } \\
\hline Anelamento & Piche & Chanfro & Testemunha \\
$1.24^{\mathrm{b}}$ & $0.85^{\mathrm{ab}}$ & $0.78^{\mathrm{a}}$ & $0.33^{\mathrm{ab}}$
\end{tabular}

Valores com letras iguais não diferem entre si ao nível de $5 \%$ de probabilidade.

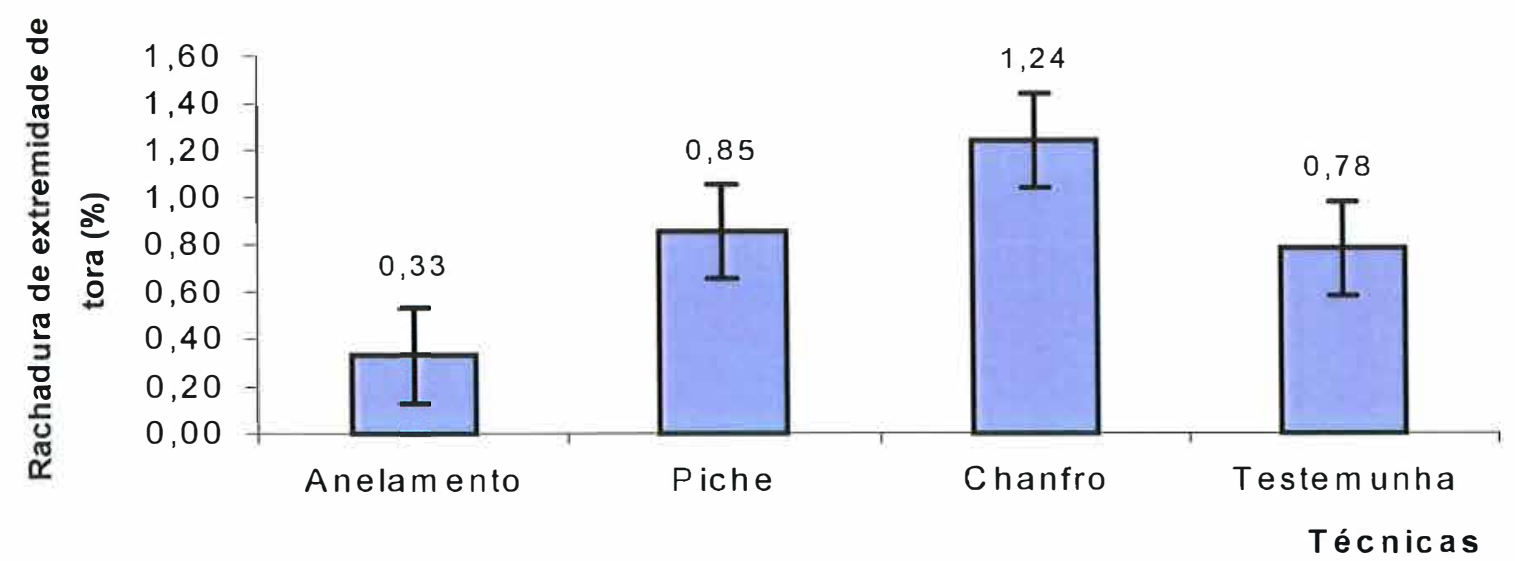

Figura 12 - Médias de índice de rachadura de extremidade de tora em função do tipo de técnica de prevenção 


\subsection{Influência da classe diamétrica da tora}

Na Figura 13, observa-se que existe uma tendência de toras com maiores diâmetros (classe 2) apresentarem valores superiores de rachaduras, exceto para anelamento. Entretanto, verificou-se que não existe diferença significativa entre as classes diamétricas, demonstrando que o diâmetro não influencia nas rachaduras de extremidade de tora. Observou-se que houve um nível mais acentuado de rachaduras na classe de maior diâmetro II, para o chanfro.

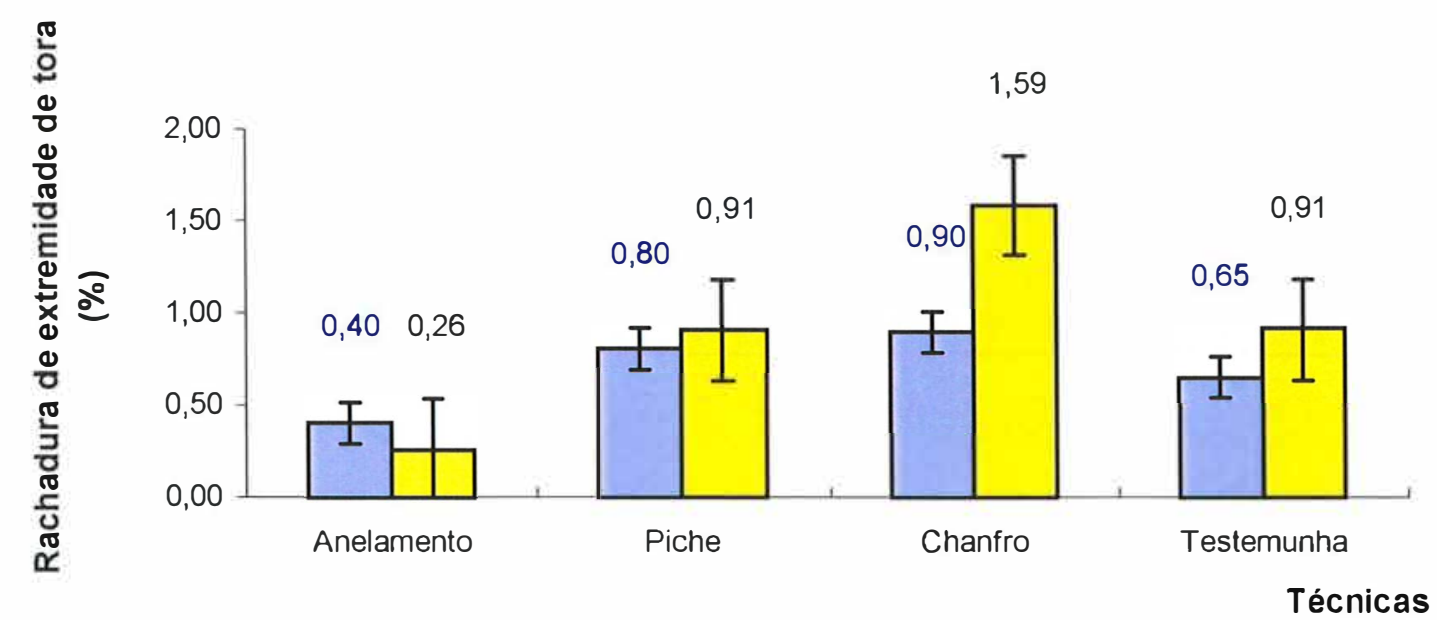

$\square C 1=18 \mathrm{~cm} \square \mathrm{C} 2=23 \mathrm{~cm}$

Figura 13 - Rachadura de extremidade de tora em função da classe diamétrica

\subsection{Influência do tempo de armazenamento na rachadura de extremidade da tora}

Apesar da ausência de diferenças significativas entre os tempos de armazenamento, verifica-se na Figura 14 que à medida que o tempo de armazenamento aumenta, ocorre uma tendência de aumento das rachaduras de extremidade de tora. Comparando as diferentes técnicas de prevenção dentro dos tempos de armazenamento, verificou-se que o anelamento foi a 
técnica que apresentou menores acréscimos no índice de rachadura para os 3 lotes.

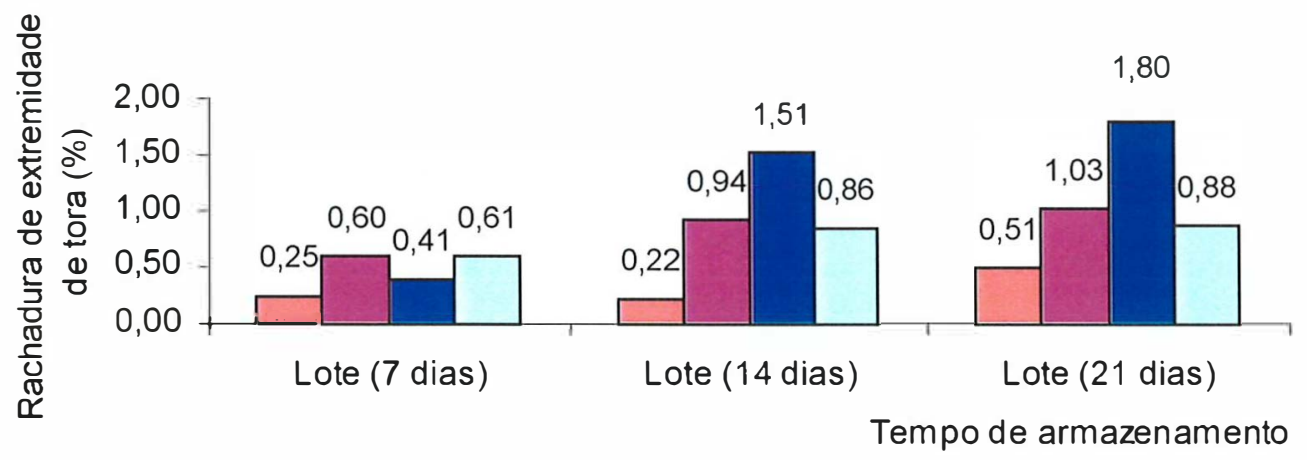

$\square$ Anelamento $\square$ Piche $\square$ Chanfro $\square$ Testemunha

Figura 14 - Índice de rachadura de extremidade de tora segundo diferentes tempos de armazenamento

\subsection{Análise estatística para o índice de rachadura de tábua (Rt)}

A Tabela 3 mostra a análise de variância efetuada para a variável rachadura de tábua. Observou-se que não existem diferenças significativas entre as classes de diâmetro, entre os tempos de armazenamento e entre as técnicas de prevenção. Constatou-se que não houve interação significativa entre os fatores.

Tabela 3. Análise de variância para variável $\mathrm{Rt}(\mathrm{cm})$

\begin{tabular}{lccc}
\hline Causa de Variação & $\mathrm{GL}$ & $\mathrm{F}$ & $\mathrm{P}>\mathrm{F}$ \\
\hline Classe de diâmetro (1) & 1 & 2.73 & 0.10 \\
Tempo de armazenamento (2) & 2 & 0.52 & 0.59 \\
Técnica de prevenção (3) & 3 & 1.47 & 0.23 \\
$1 \times 2$ & 2 & 1.30 & 0.27 \\
$1 \times 3$ & 3 & 0.64 & 0.58 \\
$2 \times 3$ & 6 & 0.27 & 0.95 \\
$1 \times 2 \times 3$ & 6 & 0.92 & 0.48 \\
(Tratamento) & $(23)$ & & \\
Resíduos & 48 & & \\
Total & 71 & & \\
\hline
\end{tabular}


Embora não tenha ocorrido diferenças significativas entre as técnicas de prevenção, observa-se na Figura 15 que o chanfro foi a técnica que mais influenciou no aumento das rachaduras de extremidade de tábuas. Por outro lado verificou-se que 0 anelamento foi a técnica que obteve 0 menor indice de rachadura de extremidade de tábua.

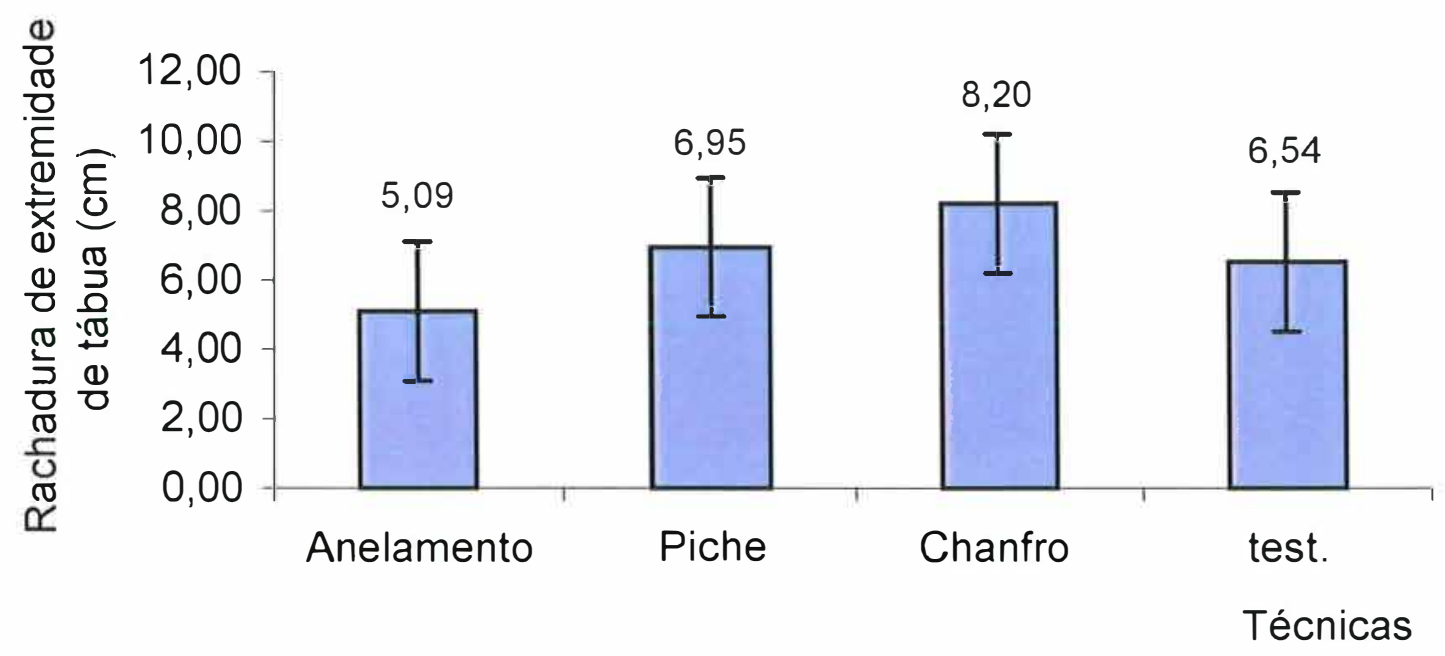

Figura 15 - Médias de índice de rachadura de extremidades de tábua em função do tipo de técnica de prevenção

\subsection{Influência do tempo de armazenamento nas rachaduras de extremidade de tábua}

Na Figura 16 pode-se constatar que embora não tenha diferença significativa entre os tempos de armazenamento em relação às técnicas de prevenção de rachaduras, verifica-se que 0 anelamento foi a técnica que apresentou os menores valores de rachadura de tábua para todos os lotes ou tempos de armazenamento. Notou-se também a nível de tendência que o chanfro apresentou o maior índice de rachadura de extremidade de tábua para 
os lotes 1 e 2 , enquanto que a testemunha foi a que obteve os maiores acréscimos de rachadura de extremidade de tábua para o lote 3.

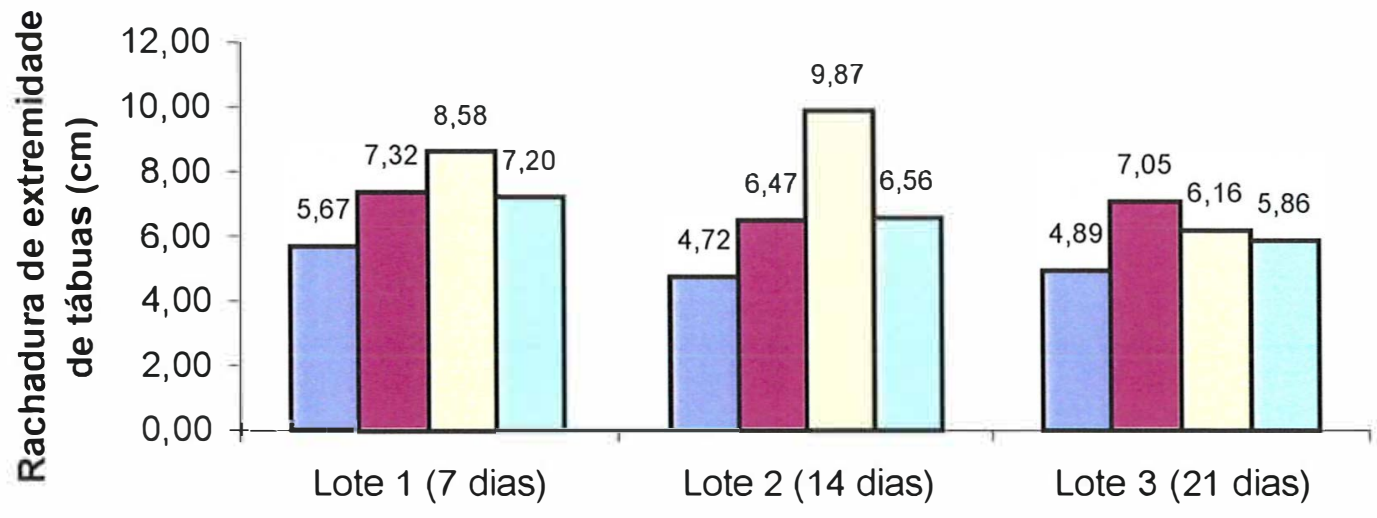

口Anelamento EPiche $\square$ Chanfro $\square$ Testemunha

Lotes

Figura 16 - Índice de rachadura de extremidade de tábua das técnicas de prevenção de rachaduras nos tempos de armazenamento

\subsection{Rachadura de extremidade de tábua em função da classe diamétrica}

Conforme mostra a Figura 17, observou-se que o diâmetro das toras não influenciou nos valores de rachaduras de extremidade de tábua. No entanto, foi possível verificar que existe uma tendência de toras de classes diamétricas maiores racharem mais.

Esse resultado está de acordo com Crespo (2000), que trabalhando com Eucalyptus grandis e Eucalyptus saligna verificou a existência de uma tendência de toras com maior diâmetro apresentarem maiores índices de rachaduras em tábuas.

Analisando as técnicas de prevenção de rachaduras, verificou-se que o chanfro foi a que apresentou maiores indices de rachaduras de extremidade de tábua nas duas classes diamétricas. 


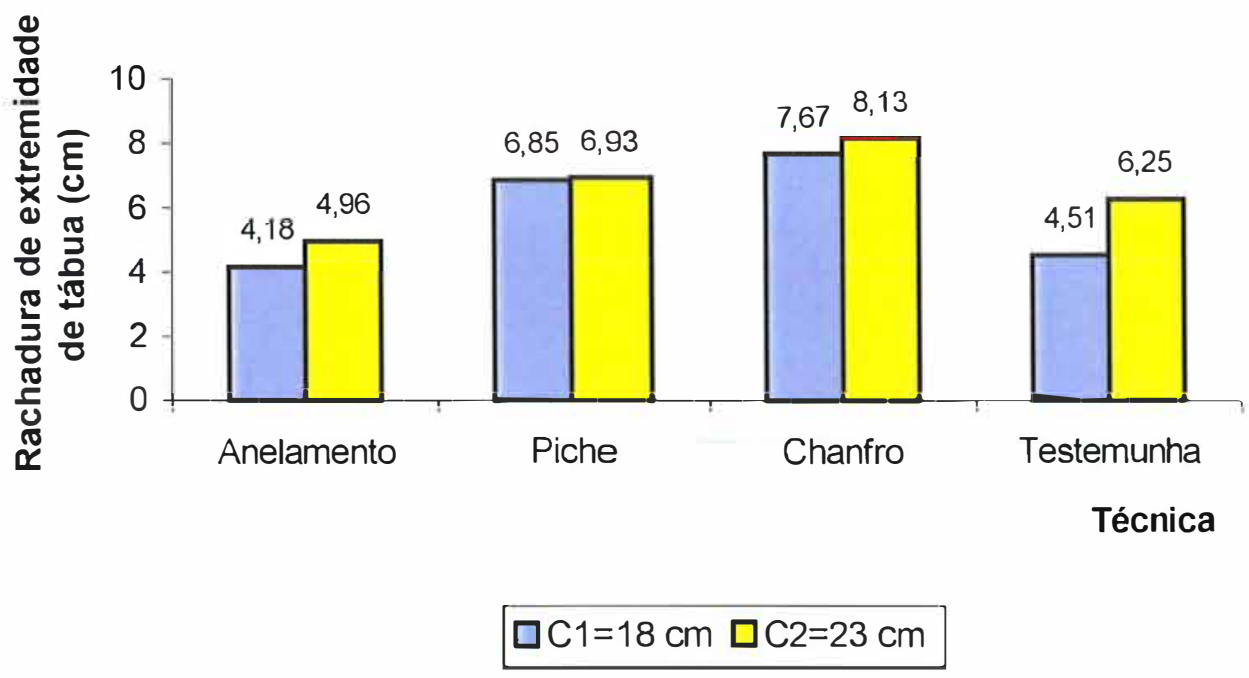

Figura 17 - Rachadura de extremidade de tábua em função da classe diamétrica

\subsection{Avaliação de perdas devido as técnicas: anelamento e chanfro}

A utilização de técnicas de anelamento e corte em chanfro com a finalidade de evitar ou reduzir as rachaduras de topo, resultou numa perda de $20 \mathrm{~cm}$ no comprimento de cada tábua oriunda da tora anelada e $18 \mathrm{~cm}$ em média para as tábuas onde as toras foram cortadas em chanfro. Isto sem levar em consideração as rachaduras de extremidade de tábua que surgiram após o anelamento e ao corte em chanfro.

A análise de variância efetuada para perda em comprimento das tábuas em relação as técnicas de prevenção é mostrada na Tabela 4, onde foi possível verificar que existe diferença significativa entre as técnicas.

Tabela 4. Análise de variância para perda de madeira no comprimento das tábuas $(\mathrm{cm})$

\begin{tabular}{lccc}
\hline Causa de Variação & GL & F & P>F \\
\hline Técnica & 3 & 2.87 & 0.03 \\
Resíduo & 383 & & \\
Total & 386 & & \\
\hline
\end{tabular}


De acordo com a Tabela 5, onde foram comparadas as médias de perda de comprimento de tábua $(\mathrm{cm})$ para as técnicas de prevenção pelo teste de Tukey ao nível de $5 \%$ de probabilidade. Constatou-se que as técnicas de prevenção Anelamento, testemunha e Piche não diferem entre si, e a técnica Anelamento diferiu significativamente da técnica de corte Chanfro.

Tabela 5. Comparação entre as médias das perdas de comprimento de tábuas (cm) pelo teste de Tukey

\section{TÉCNICAS}

\begin{tabular}{cccc}
\hline Anelamento & Piche & Chanfro & Testemunha \\
$27.09^{\mathrm{b}}$ & $40.50^{\mathrm{ab}}$ & $45.81^{\mathrm{a}}$ & $38.83^{\mathrm{ab}}$ \\
\hline
\end{tabular}

Valores com letras iguais não diferem entre si ao nivel de $5 \%$ de probabilidade.

As perdas em comprimento linear de tábuas foram medidas de acordo com as Figuras 18 e 19 para o anelamento e chanfro, respectivamente. Mediu-se a perda efetiva causada pelas rachaduras $\left(R_{1}+R_{2}\right)$ e ainda a perda devido a técnica aplicada $(P)$.

$\mathrm{R}_{1}$

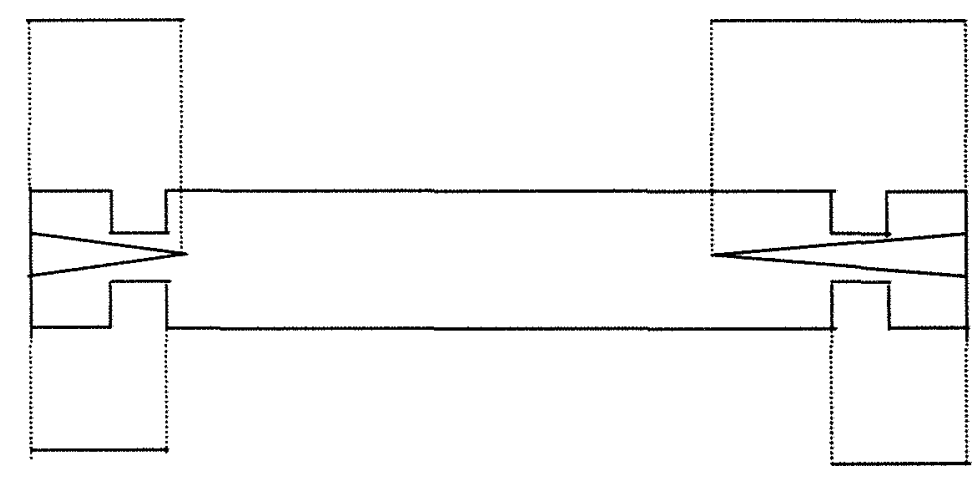

$\mathrm{P}$
R,

$P$

Figura 18 - Esquema de medição das perdas de tábuas em comprimento para o anelamento 


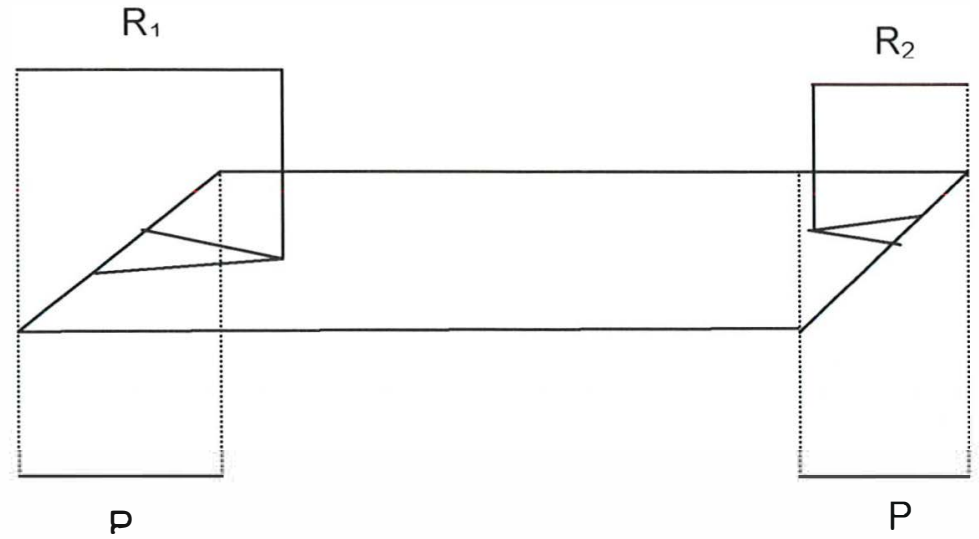

Figura 19 - Esquema de medição das perdas de tábuas em comprimento para o chanfro

A Figura 20 apresenta as perdas médias no comprimento das tábuas, onde foi possível verificar que o anelamento apresentou a menor perda em relação as demais técnicas de prevenção de rachadura, entretanto, o chanfro foi a técnica que ocasionou as maiores perdas em comprimento de tábuas causadas por rachaduras de extremidade de tábuas. Portanto, foi possivel constatar que 0 anelamento perde mais em comprimento em decorrência da técnica aplicada do que pela rachadura efetiva.

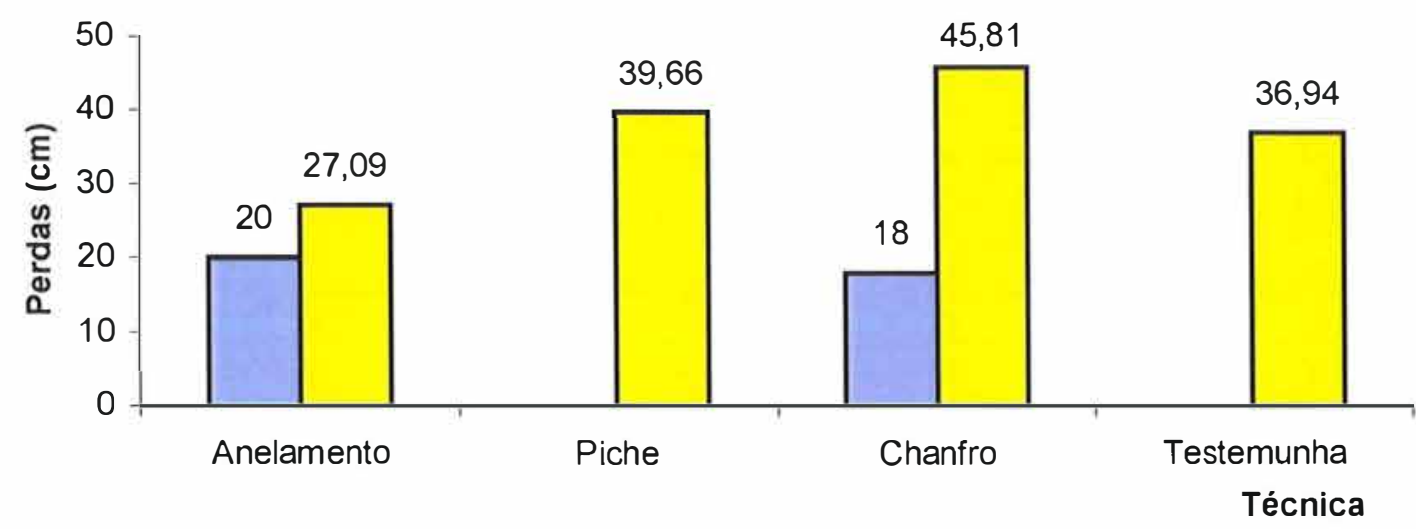

$\square P \square R 1+R 2$

Figura 20 - Perda média das tábuas em comprimento em função das técnicas 
4.8 Estudo da taxa de propagação das rachaduras, no sentido radial e longitudinal da tora

A metodologia proposta para realização deste estudo de propagação de rachadura ao longo da tora demonstrou não ser muito eficiente para a identificação da rachadura crítica. 


\section{CONCLUSÕES}

Com base nos resultados obtidos concluiu-se que:

$\mathrm{O}$ indice de rachadura de extremidade de tora foi maior nas toras que receberam piche, corte em chanfro e na testemunha, e menor nas que foram aneladas.

A classe de diâmetro da tora não teve influência significativa nos valores do índice de rachadura de extremidade de tora. No entanto, esse índice cresce com o aumento do diâmetro, exceto para a técnica de anelamento.

O tempo de armazenamento não influenciou significativamente na progressão de rachadura de extremidade de tora, porém, houve uma tendência de aumento das rachaduras à medida que o tempo de armazenamento aumentava.

Ainda a nível de tendência, o anelamento foi a técnica que sofreu menores acréscimos no indice de rachadura de extremidade de tora ao longo do tempo.

As técnicas de prevenção de rachaduras não tiveram influência significativa nas rachaduras de tábua. Entretanto, o chanfro foi a técnica que possibilitou a maior média de rachadura de extremidade tábua. 
Embora o tempo de armazenamento não tenha influenciado significativamente no aparecimento de rachaduras de extremidade de tábua, o anelamento foi a técnica que apresentou os menores índices de rachadura de tábuas para o tempo de armazenamento 7 dias, enquanto que 0 chanfro apresentou os maiores valores de rachaduras de extremidade de tábua para os tempos 7 e 14 dias.

Não foi observada influência significativa do diâmetro da tora nas rachaduras de tábua. Porém, houve uma tendência das toras com maior diâmetro racharem mais. O chanfro apresentou os maiores índices de rachaduras de tábuas nas duas classes.

O anelamento foi a técnica que apresentou menor perda no comprimento de tábuas em relação as demais técnicas. O chanfro obteve as maiores perdas em comprimento de tábuas, porém o anelamento apresentou maior perda em função da técnica do que pelas rachaduras de extremidade de tábua.

A metodologia proposta para a quantificação e progressão das rachaduras ao longo do tempo, baseada na utilização de tintas de diferentes cores em diferentes tempos de armazenamento, não suficiente para a determinação da rachadura crítica. Isto pode ser explicado pelo de que a rachadura se afunila ao longo da tora. Por isso, a tinta que despejada num determinado tempo impedia a passagem das demais tintas nos tempos subsequentes. 


\section{REFERÊNCIAS BIBLIOGRÁFICAS}

AGUIAR, O.J.R. Prevenção e controle das rachaduras de topo em tora de Eucalyptus grandis hill ex maiden. Piracicaba, 1986. 92p. Dissertação (Mestrado). Escola Superior de Agricultura "Luiz de Queiroz", Universidade de São Paulo.

ANDRADE, E.N. O eucalipto. 2. e. Jundiaí: Companhia Paulista de Estradas de Ferro, 1961.664p.

ASSIS, T.F. Aspectos do melhoramento de Eucalyptus para obtenção de produtos sólidos da madeira. In: TÉCNICAS DE ABATE, PROCESSAMENTO E UTILIZAÇÃO DA MADEIRA DE EUCALIPTO, VIÇOSA,1999. Workshop. VIÇOSA: DEF/SIF/UFVIIEF, 1999, p. $61-72$.

ASSIS, T.F. Estratégias de melhoramento para a obtenção de madeira de qualidade para laminação e serraria. In: SEMINÁRIO MADEIRA DE EUCALIPTO: TENDÊNCIAS E USOS, Curitiba,2001. Anais. Curitiba: FUPEF/UFPR, 2001. p. 1 - 18

BARCHET, V.G. Potencialidade de espécies de Eucalyptus para produção de madeira serrada. Piracicaba, 2001. 166p. Dissertação (Mestrado). Escola Superior de Agricultura "Luiz de Queiroz", Universidade de São Paulo. 
BARISKA, M. A method for predicting timber quality in Eucalyptus. In: MANAGEMENT OF Eucalyptus IN SOUTH AFRICA, Stellenbosch, 1990. Proceedings. Stellenbosch: Southern African Institute of Forestry,1990. p.215-228.

BARNACLE, J.E.; GOTTSTEIN, J.W. Control of end-splitting in round timber: a promising new method. Forest Products Technical Notes. CSIRO, v.4, n.8, p.8, 1968.

CHAFE, S. C. Growth stress in trees. Australian Forest Research. CSIRO, v.9, p.203-223, 1979.

CONRADIE, W. E. Utilization of South African grown Eucalyptus grandis (W. Hill ex Maiden) as veneer logs. Part. 1 Control of end-splitting in venner logs. CSIR, 1980. 27 p. (Special Report, 206).

CRESPO, E. A. Tensão de crescimento e suas consequências, controláveis e não controláveis, no desdobro e secagem do Eucalyptus grandis e Eucalyptus saligna. Piracicaba, 2000. 90p. Dissertação (Mestrado). Escola Superior de Agricultura "Luiz de Queiroz", Universidade de São Paulo.

DEL MENEZZI, C. H. S.; NAHUZ, M. A. R. Técnicas de desdobro utilizadas para madeira de eucalipto - uma revisão bibliográfica. Revista árvore, v. 22 , n. 3, p. $415-428,1998$.

DE VILLIERS, A.M. Utilization problems with same Eucalypts in South Africa. South African Forestry Journal, n.109, p.47-53, 1973. 
FERNANDES, P.S.; LORSHEIM, S.M.B.; ROCHA, F.T.; MONTAGNA, R. G.; COUTO, H. T.Z. Tensões de crescimento em procedências de Eucalyptus grandis Hill Ex Maiden e suas relações com características das fibras e densidade básica. Revista do Instituto Florestal, v.1, n.1, p.215-234, 1989.

FERRAND, J.C. Growth stresses and silviculture of Eucalypts. Australian Forest Research, v.1, n.1, p.75-81. 1983.

GALVÃO, A.P.M. Aspectos da utilização da madeira de eucalipto no Brasil Seu aproveitamento em serraria. Boletim Informativo IPEF, v.4, n.12, p.1-23, Jul. 1976.

GARCIA, J. N. Processamento mecânico do Pinus e Eucalyptus. Piracicaba: ESALQ/Departamento de Ciências Florestais, 1988. 20p.

GARCIA, J. N. Estados de tensão em árvores e de deformação em peças de madeira serrada. São Paulo, 1992. 262p. Tese (Doutorado). Escola Politécnica, Universidade de São Paulo.

GARCIA, J. N. Técnicas de desdobro de Eucalipto. In: SEMINÁRIO INTERNACIONAL DE UTILIZAÇÃO DA MADEIRA DE EUCALIPTO PARA SERRARIA, São Paulo, 1995. Anais. Piracicaba: IPEF/IPT, 1995. p. 59-67.

GARCIA, J. N. An Alternative Sawmill Plant To improve Eucalyptus lumber Quality.IN: INTERNATIONAL WOOD MACHINING SEMINAR. Vancoucer, 1997. 13, Proceedings Vancoucer-Canadá: Vancouver University of British Columbia, 1997. p. 865-874. 
JACOBS, M.R. The fibre tension of woody stems with special reference to the genus Eucalyptus. Canberra: Commonwealth Government Printer, 1938. $39 \mathrm{p}$.

KUBLER, H. Growth stresses in trees and Related Wood Properties. Forestry Abstracts, v.10, n.3, p.61-119, 1987.

LIMA, I.L. Variação das propriedades indicativas da tensão de crescimento em função da posição na árvore e da intensidade de desbaste. Piracicaba, 2000. 90p. Dissertação (Mestrado). Escola Superior de Agricultura "Luiz de Queiroz", Universidade de São Paulo.

LISBÔA, C. D. J. Estudo das tensões de crescimento em toras de Eucalyptus grandis Hill. ex Maiden. Curitiba, 1993. 298p. Tese (Doutorado) Universidade Federal do Paraná.

MALAN, F.S. The control of end splitting in sawlogs: a short literature review. South African Forest Journal, v. 109, p. 14-28, 1979.

MALAN, F.S. Eucalyptus improvement for lumber production. In: SEMINÁRIO INTERNACIONAL DE UTILIZAÇÃO DA MADEIRA DE EUCALIPTO PARA SERRARIA, São Paulo, 1995. Anais. São Paulo : IPEF/IPT/IUFRO/ESALQUSP, 1995. p. 1-19.

MATTHECK, R. G.; WALTHER, F. A new felling technique to avoid end splitting of deciduous trees. Karlsruhe: Germany: Karlsruhe Nuclear Research Center, Institute for Materials Research II, 1991. p. 110-113. 
MIRANDA, M.J.A.C.; NAHUZ, M.A.R. Estudo da influência do espaçamento de plantio de Eucalyptus saligna Smith nos índices de rachamento após o desdobro e após a secagem. Scientia florestalis, n. 55, p. $107-116$, jun. 1999.

NICHOLSON, J. E. Growth stress differences in Eucalypts. Forest Science, v.19, n.3, p. $169-174$, set. 1973.

OLIVEIRA, J.T.S.; HELLMAISTER, J.C.; TOMAZELLO FILHO, M. Eucalyptus wood characterization for construction in Brazil. In: THE FUTURE OF Eucalyptus FOR WOOD PRODUCTS IN AUSTRALIA. LAUNCESTON, 2000. Proceedings. LAUNCESTON. IUFRO, 2000, p. 98-105.

PANDEY, C. N.; GAUR, B. K.; KANNOJI, H. C.; CHANDRA, A. A new approach to seasoning of eucalypts hybrid (Eucalyptus tereticornis). Indian Forester Dehra, v. 110, n. 3, 1984, p. 117-121.

PANDEY, C. N. Potential of plantation grown Eucalyptus as source of raw material to wood based industry in India. In: THE FUTURE OF EUCALYPTS FOR WOOD PRODUCTS IN AUSTRALIA. LAUNCESTON, 2000 Proceedings. LAUNCESTON.IUFRO, 2000,p.45-50..

PANSHIN, A. J.: ZEEUW, C. Textbook of wood technology. 4. ed. New York: Mcgraw-Hill, 1982. 722p.

PIO, N.S. Avaliação da Madeira de Eucalyptus scabra (Dum-Cours) e Eucalyptus robusta (Smith) na produção de painéis de compensados. Curitiba, 1996. 101p. Tese (Mestrado) - Universidade Federal do Paraná. 
PONCE, R.H. Madeira serrada de eucalipto: desafios e perspectivas. In: SEMINÁRIO INTERNACIONAL DE UTILIZAÇÃO DA MADEIRA DE EUCALIPTO PARA SERRARIA, São Paulo, 1995, Anais. Piracicaba: IPEF/IPT, 1995. p.50-58.

ROCHA, M. P. Eucalyptus grandis Hill ex Maiden e Eucalyptus dunni Maiden como fontes de matéria prima para serraria. Curitiba, 2000. 185p. Tese (Doutorado) - Universidade Federal do Paraná.

ROCHA, M. P. Madeira serrada de Eucalyptus dunnii. In: SÓLIDOS DE EUCALIPTO: AVANÇOS CIENTÍFICOS E TECNOLÓGICOS. Lavras, 2002. 65p. Anais. Lavras: FAEPE, 2002. 65p.

ROZAS MELLADO, E.C.E. Contribuição ao desenvolvimento tecnológico para utilização de madeira serrada de Eucalyptus grandis Hill ex Maiden na geração de produtos com maior valor agregado. Curitiba, 1993. 133p. Dissertação (Mestrado) - Universidade Federal do Paraná.

SANTINI, E. J. Qualidade de madeira seca. In: SEMINÁRIO SOBRE SECAGEM DE MADEIRA, 1., 1992. Anais. Santa Maria: UFSM/ CEPEF/FATEC, 1992. $100 p$.

SILVA, J.C. Caracterização da madeira de Eucalyptus grandis Hill ex. Maiden, de diferentes idades, visando a sua utilização na indústria moveleira. Curitiba: 2002. 181p. Tese (Doutorado) - Universidade federal do Paraná.

SHACHT, L. Variação de caracteres e suas implicações para o melhoramento genético da madeira serrada em Eucalyptus urophylla. Piracicaba, 1998. 74p. Tese (Mestrado) - Escola Superior de Agricultura "Luiz de Queiroz", Universidade de São Paulo. 
SCHACHT,L.; GARCIA,J.N. Variação entre e intra clones nas rachaduras de topo em Eucalyptus urophylla S.T.Blake. In: IUFRO CONFERENCE ON SILVICULTURE AND IMPROVEMENT OF EUCALYPTS, Salvador, 1997. Anais. Colombo: EMBRAPA/CNPF, 1997. v.3, p.401-404.

SCHACHT, L.; GARCIA, J.N ; VENCOVSKY, R. Variação genética de indicadores de tensão de crescimento em clones de Eucalyptus urophylla. Scientia Florestalis, n.54, p.55-68, dez. 1998.

STCP, Engenharia de projetos Ltda. http://www.stcp.com.br. (20 jun. 2000).

TANTICHAIBORIBOON, V.; COOK, R.D. Effect of shape of cut on growth stress induced cracking in cut timber. Rep CEEM-76-101. Madisson: College Engenering University Winsconsin, 1977. 245p.

VIGNOTE, S.; MOLINERO, I.; GERARD, J.; DIEZ, M.R. Estudio de las Tensiones de Crescimento Del Eucalyptus globulus labill En Galicia y Su Relacion com Las Caracteristicas de La Estacion y Morfológicas Del próprio Arbol. Investigacion Agrário: Sistemas e Recursos Florestales, v.5, n.1, p. 154-165, 1996.

WAUGH, G. Sawing of young, fast-grown Eucalyptus. In: SEMINÁRIO INTERNACIONAL - PRODUTOS SÓLIDOS DE MADEIRA DE ALTA TECNOLOGIA, 1. Viçosa, 1998. Anais. Viçosa: MG. Editora Folha de Viçosa, 1998, p. 69-81.

WILHELMY, V; KUBLER, $\mathrm{H}$. Stresses and checks in log ends; from relived growth stresses, Wood Science, v.6, n.2, p. p. 69-81 136-142, 1973. 
WILKINS.A.P. Nature and origin of growth stress in trees. Australian Forestry, v.49, n.1, p.56-62, 1986. 